\title{
Alternative Substrate Metabolism in Yarrowia lipolytica
}

\author{
Michael Spagnuolo ${ }^{1}$, Murtaza Shabbir Hussain ${ }^{1}$, Lauren Gambill ${ }^{1,2}$ and Mark Blenner ${ }^{1 *}$ \\ ${ }^{1}$ Department of Chemical and Biomolecular Engineering, Clemson University, Clemson, SC, United States, ${ }^{2}$ Program in \\ Systems, Synthetic, and Physical Biology, Rice University, Houston, TX, United States
}

Recent advances in genetic engineering capabilities have enabled the development of oleochemical producing strains of Yarrowia lipolytica. Much of the metabolic engineering effort has focused on pathway engineering of the product using glucose as the feedstock; however, alternative substrates, including various other hexose and pentose sugars, glycerol, lipids, acetate, and less-refined carbon feedstocks, have not received the same attention. In this review, we discuss recent work leading to better utilization of alternative substrates. This review aims to provide a comprehensive understanding of the current state of knowledge for alternative substrate utilization, suggest potential pathways identified through homology in the absence of prior characterization, discuss recent work that either identifies, endogenous or cryptic metabolism, and describe metabolic engineering to improve alternative substrate utilization. Finally, we describe

OPEN ACCESS

Edited by:

Ryan S. Senger,

Virginia Tech, United States

Reviewed by:

Rodrigo Ledesma-Amaro,

Imperial College London,

United Kingdom

Zengyi Shao,

lowa State University, United States

${ }^{*}$ Correspondence:

Mark Blenner

blenner@clemson.edu

Specialty section:

This article was submitted to Microbial Physiology and Metabolism,

a section of the journal

Frontiers in Microbiology

Received: 13 October 2017

Accepted: 07 May 2018

Published: 25 May 2018

Citation:

Spagnuolo M, Shabbir Hussain M, Gambill L and Blenner M (2018) Alternative Substrate Metabolism in Yarrowia lipolytica.

Front. Microbiol. 9:1077.

doi: 10.3389/fmicb.2018.01077 the critical questions and challenges that remain for engineering Y. lipolytica for better alternative substrate utilization.

Keywords: Yarrowia lipolytica, pentose, hexose, xylose, fat, waste, acetate, metabolic engineering

\section{INTRODUCTION}

The oleaginous yeast Yarrowia lipolytica has great potential for the production of a large range of biochemicals and intermediates. As an oleaginous yeast, its metabolism is well-primed for the biosynthesis of triacylglycerides (TAGs) when grown in nutrient-limited conditions. This requires high flux through acetyl-CoA, making it a good production host for molecules that likewise require acetyl-CoA. There are numerous examples of metabolic engineering efforts to make economically useful amounts of products, including TAGs, omega-3 rich TAGs, fatty acid derivatives, carotenoids, and organic acids (Yuzbashev et al., 2010; Xue et al., 2013; Blazeck et al., 2014; Qiao et al., 2015; Ryu et al., 2015; Wang et al., 2016; Xu et al., 2016; Gao et al., 2017; Kildegaard et al., 2017; Sabra et al., 2017; Schwartz et al., 2017a; Xie et al., 2017; Sagnak et al., 2018). Several recent reviews have thoroughly covered metabolic engineering efforts, as well as advances in the genetic engineering toolkit that enables such work (Blazeck and Alper, 2013; Hussain et al., 2016; Adrio, 2017; Yan et al., 2017). In most cases, refined glucose is used as the substrate for Y. lipolytica growth and product formation. There are many alternative substrates that can and should be considered due to their relative low costs, additional sustainability benefits, and in some cases, better conversion to products. The use of polysaccharides, less-common monosaccharides, and other select substrates, as well as the associated engineering efforts, have been covered in a recent review (Ledesma-Amaro and Nicaud, 2016a). In this review, we expand on the set of alternative substrates that have been used for Y. lipolytica growth and bioproduction. We further provide examples where metabolic engineering and synthetic biology were applied to enhance alternative substrate utilization. 


\section{HEXOSE SUBSTRATES}

\section{Mannose}

Mannose is a C-2 epimer of glucose and belongs to the family of aldo-hexoses. In nature, it exists in either its predominant, sweet tasting $\alpha$-form or in its less common, bitter tasting, $\beta$-anomeric form. D-Mannose is commonly used as a nutritional supplement and, in some instances, as an anti-fungal therapy because of its relative toxicity. Mannose has been shown to be readily fermented by Saccharomyces cerevisiae (Gottschalk, 1946; Du Preez et al., 1986), although it has been the subject of relatively fewer studies in comparison to other aldo-hexose sugars. While metabolism of mannose is known to occur in Y. lipolytica (Coelho et al., 2010), the complete metabolic pathway has not yet been fully elucidated.

Following transport of mannose into the cell, one pathway for mannose utilization is by isomerization to fructose; however, such isomerases are predominantly found in bacteria and do not exist in yeast (Rajesh et al., 2012; Sigdel et al., 2015). Not surprisingly, BLAST analysis revealed no homologs of bacterial mannose isomerases in Y. lipolytica (all BLAST analysis performed under default parameters unless source is noted). A more common mechanism for mannose metabolism is specific mannose phosphorylation to mannose-6-phosphate by a mannokinase (MK2, Figure 1). These enzymes are found in some bacteria and higher-level eukaryotic systems (Fukuda et al., 1984). BLAST analysis again revealed no homologs in $Y$. lipolytica, suggesting the absence of a specific enzyme. In S. cerevisiae, mannose is phosphorylated by hexokinases (HKs), which have broad specificity. Two of these HK isozymes, HXK1 and HXK2, act on a broad range of sugars including keto and aldohexoses (Rodriguez et al., 2001; Subtil and Boles, 2012). Meanwhile the third isozyme, glucokinase (GLK1), possesses a more stringent specificity toward aldohexoses, including mannose, and lacks activity toward fructose (Maitra, 1970; Gancedo et al., 1977). BLAST analysis of the $S$. cerevisiae glucokinase and HK revealed two orthologs in Y. lipolytica, ylHXK1 (YALI0B22308g), and $y l G L K 1$ (YALI0E15488g). Given the promiscuity of the kinases in S. cerevisiae (Sharifpoor et al., 2011), it is likely that these two HKs are involved in mannose phosphorylation, although this has yet to be directly shown.

While the use of mannose as a carbon source has received limited attention, the role of mannose in glycoprotein biogenesis has been well studied (Ezekowitz et al., 1990; Chiba et al., 1998; Hamilton et al., 2003; Zhu et al., 2009; Tiels et al., 2012). More recently, Y. lipolytica has been explored as a host for the production of therapeutic mannoproteins due to its efficient heterologous protein secretory capabilities and the growing set of genetic tools available, such as a suite of promoters and terminators (Thevenieau et al., 2009; Blazeck et al., 2011, 2013; Curran et al., 2015; Shabbir Hussain et al., 2016, 2017), pooled promoters (Dulermo et al., 2017), secretion markers (Nicaud et al., 2002; Madzak et al., 2004), Golden Gate assembly (Celińska et al., 2017), and CRISPR systems (Gao S. et al., 2016; Schwartz et al., 2016, 2017b). Mannosylphosphorylated $\mathrm{N}$-glycans are a precursor to produce mannose-6-phosphate containing glycoproteins. A single gene in Y. lipolytica, ylMpo1, was found to efficiently catalyze a mannophosphorylation reaction in a single step (Park et al., 2011) whereas this reaction is a two-step enzymatic process in S. cerevisiae (Gil et al., 2015). While $N$-glycosylated mannoproteins are outside the scope of this review, the above example demonstrates one method by which $Y$. lipolytica could effectively assimilate mannose into protein therapeutics.

\section{Galactose}

Galactose is a C-2 epimer of glucose and belongs to the family of aldo-hexoses. D-Galactose is the only natural isomer and is abundant in plant cell biomass and milk. The most predominant mechanism for galactose metabolism in yeast is the Leloir pathway. This pathway shuttles galactose through a series of sequential enzymatic steps to produce glucose-6-phosphate that can then be funneled into glycolysis. S. cerevisiae has been used as a model organism for complete characterization of the Leloir pathway (Douglas and Hawthorne, 1964; Ostergaard et al., 2000; Timson, 2007). Another pathway for galactose metabolism has been identified in filamentous fungus, Aspergillus niger, that involves a series of energy intensive redox reactions to convert galactose to D-fructose (Mojzita et al., 2012).

Recently, all enzymes implicated in the Leloir pathway were identified in the $Y$. lipolytica genome; however, the French strain, W29 and the corresponding PO1 auxotrophs, do not grow on galactose substrate despite the presence of predicted Leloir pathway genes (Lazar et al., 2015). Lazar et al. (2015) determined that overexpression of three native genes, ylGAL1 (YALI0C13090g), ylGAL7 (YALIOF23947g), and $y l G A L 10 E$ (YALIOE26829g), were needed for growth on galactose (Figure 1). Expression of these genes under the strong, constitutive translation elongation factor $1-\alpha($ TEF $1-\alpha)$ promoter resulted in growth comparable to growth using glucose. Furthermore, growth on glucose and galactose enabled galactose uptake, although glucose was metabolized at a relative higher rate. Complementation of the three $y l G A L$ genes in the $\triangle s c G A L$ strain restored galactose metabolism confirming that the identified $Y$. lipolytica orthologs are, in fact, genes belonging to the Leloir pathway.

While the structural components of the Leloir pathway exist in Y. lipolytica, a BLAST analysis for S. cerevisiae orthologs of regulatory proteins, namely $s c G A L 3, s c G A L 4, s c G A L 80$, and scGAL11, were not identified (Suzuki et al., 1988; Lazar et al., 2015). Furthermore, the 17 bp scGAL4 consensus binding sequence was also not found in any of the $y l G A L$ promoters. These results suggest that promoters regulating the $Y$. lipolytica genes in the Leloir pathway are not inducible by galactose in contrast to $S$. cerevisiae Leloir pathway genes (John and Davis, 1979; Schultz et al., 1987). A plausible explanation for the above results is that there is a cryptic regulatory mechanism in $Y$. lipolytica that is evolutionarily divergent from S. cerevisiae.

Catabolite repression of galactose by glucose in S. cerevisiae has been extensively studied (Zimmermann and Scheel, 1977; Ma and Botstein, 1986; Escalante-Chong et al., 2015). This happens by repression of the GAL3 transcriptional factor necessary for inducing the GAL gene cluster (Bajwa et al., 1988). scGAL3 is an ohnolog of scGAL1 that has evolved to function as a transcription factor by loss of two amino acids that abrogate its enzymatic 


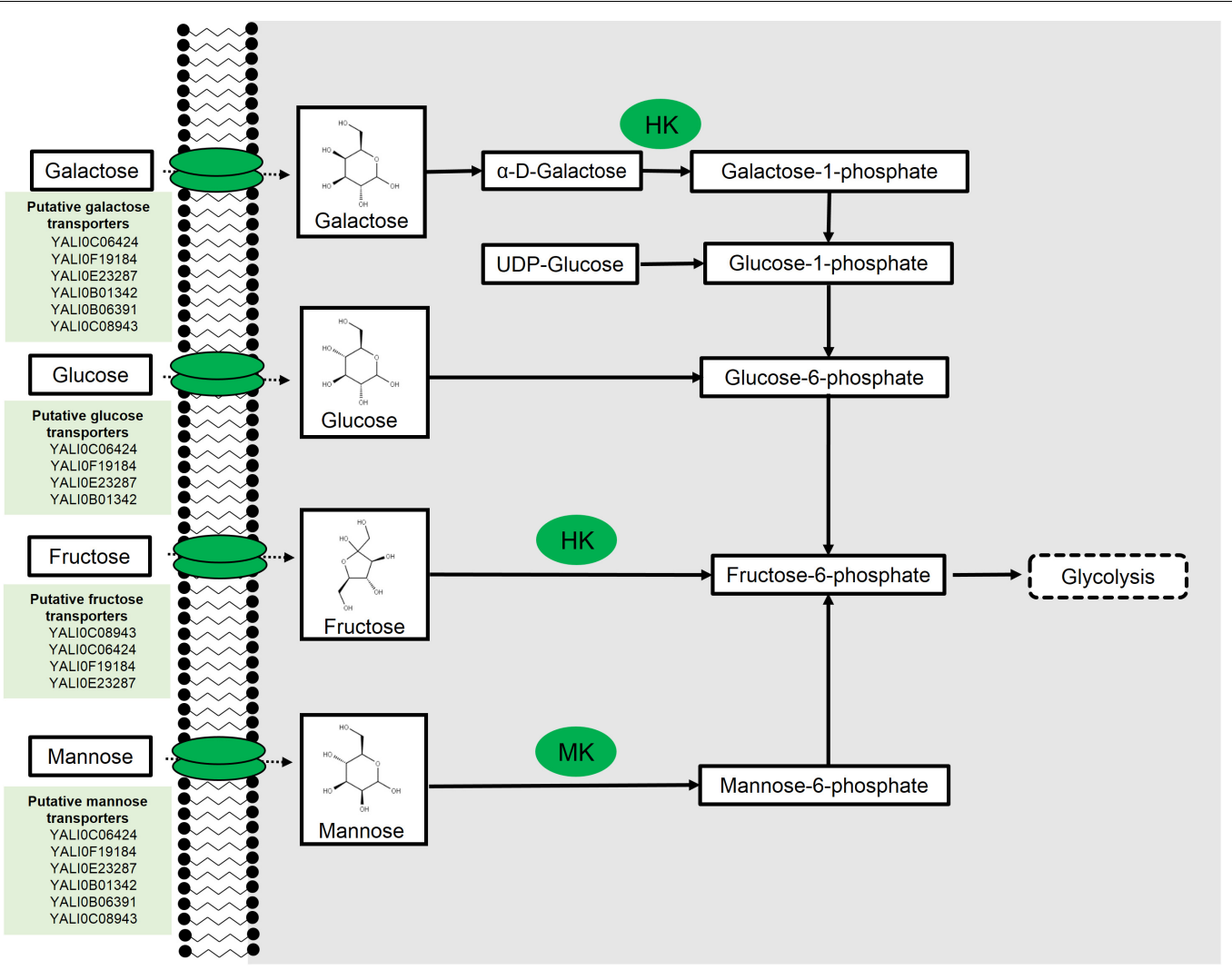

FIGURE 1 | Hexose metabolism in Yarrowia lipolytica. Hexokinase (HK) and mannokinase (MK). Putative transporter results from Lazar et al. (2017).

activity (Platt et al., 2000). Lazar et al. (2015) demonstrated that ylGAL1 is not a transcriptional regulator, but rather only possessed HK activity. The fact that all identified $y l G A L$ genes were expressed in glucose strongly suggests that $Y$. lipolytica regulates galactose with a very different mechanism compared to S. cerevisiae or other fungal species such as A. nidulans (Drysdale et al., 1993).

\section{Fructose}

Fructose is a ketohexose found predominantly in sweet fruits and honey that has been used as a sweetener, as well as a preservative. Fructose metabolism is well understood, requiring phosphorylation of fructose to fructose-6-phosphate by a $\mathrm{HK}$ (Figure 1). In Y. lipolytica, ylHK1 is mainly responsible for catalyzing this step. Overexpression of $y l H K 1$ resulted in up to $55 \%$ lipid accumulation from fructose under nitrogen-limited conditions (Lazar et al., 2014).

Metabolism of fructose in $Y$. lipolytica has gained much attention because of its widespread abundance and low cost in molasses, sucrose, and corn syrup. The disaccharide sucrose is made of the monosaccharides glucose and fructose. Y. lipolytica is naturally unable to metabolize sucrose because it lacks an invertase enzyme required for the cleavage of the disaccharide. The recombinant scSUC2 gene was first used as a positive selection marker for screening of $Y$. lipolytica transformants (Nicaud et al., 1989a) and more recently, was integrated into common W29-derived strains, such as Polf (Nicaud et al., 1989b). scSUC2 expression and secretion was enhanced using the strong $p T E F$ promoter to drive expression and an optimized signaling sequence (Hong et al., 2012). This new Y. lipolytica strain resulted in superior intracellular and extracellular invertase activity followed by more robust growth on sucrose (Lazar et al., 2013).

With the extracellular secretion of invertase, Y. lipolytica grown on sucrose was able to uptake both glucose and fructose, although glucose was preferred (Moeller et al., 2012). When $Y$. lipolytica was grown on either fructose or glucose as the sole carbon source, however, uptake of both carbon sources occurred at the same rate, hinting that yeast possess similar uptake and transport mechanisms for glucose and fructose. Furthermore, Moeller et al. (2012) showed that the glucose uptake rate was reduced when fructose was already present in the culture media. Fructose concentrations ranging from as low as $5 \mathrm{~g} / \mathrm{L}$ to as high as $85 \mathrm{~g} / \mathrm{L}$ were tested and resulted in glucose uptake inhibition.

\section{Hexose Transporters}

Because sugars are not able to freely transport across the cell membrane, an active transport mechanism is needed to facilitate the process. Transporter proteins exist at the interface of the cell membrane that allow for the selective uptake of sugars. In yeast, these transporters tend to be more promiscuous, where generally one transporter is capable of transporting multiple types of sugar 
often with preference for one (Colabardini et al., 2014; Jordan et al., 2016).

In $Y$. lipolytica, there are at least 24 sugar transporters with 6 of these being identified strictly as hexose transporters (Lazar et al., 2017). These hexose transporters were identified from heterologous expression of the Y. lipolytica transporters in a knockout strain of $S$. cerevisiae incapable of sugar uptake. These transporter findings are summarized in Figure 1. While such experiments are common, they can miss true positives due to either poor expression or folding in heterologous systems, leading to a measured lack of functionality. Another interesting fact revealed by Lazar and team was the existence of inter-strain variability toward the uptake of fructose between the W29 and the H222 German strain. The W29 strain was less capable of growth in fructose compared to H222, which demonstrated robust growth in fructose as the sole carbon source (Lazar et al., 2014). Mining of the draft genome of both W29 and $\mathrm{H} 222$ revealed a pseudogene (YALIOC04686g) in W29 with strong sequence similarity to H222's functional fructose transporter. Furthermore, amino acid polymorphisms were found in eight of the transporters between the two strains that could potentially explain an evolutionary divergence of the H222 strain that resulted in modifications to transporters that enable better fructose uptake.

Sugar transporters have been extensively studied in S. cerevisiae (Luyten et al., 2002; Batista et al., 2004; Rintala et al., 2008). There are 20 identified genes in the family of hexose transporters for $S$. cerevisiae, of which 18 are bona fide transporters (HXT1-17 and GAL2) and two genes encode sensor proteins (SNF3 and RGT2). The expression pattern of these genes is also strongly dependent on oxygen conditions (Rintala et al., 2008). Furthermore, the regulation and expression of these transporters are highly complex, requiring the involvement of several transcription factors. One strategy to improve glucose uptake rate, and thereby improve biochemical production, is to overexpress the high affinity HXT7 transporter (Kim et al., 2015). BLAST analysis of the $s c H X T 7$ protein against the Y. lipolytica genome revealed three of the six currently identified hexose transporters (YALI0F19184p, YALI062424p, and YALI0C09843p) with the former having highest sequence homology to HXT7. The same group showed that the rate of glucose uptake was improved with the overexpression of the GCR1 transcription factor due to its role in inducing the low-affinity HXT1 transporter thought to be critically important at the beginning of fermentation (Luyten et al., 2002). BLAST analysis for a homolog of GCR1 in Y. lipolytica yielded no matches, indicating a potentially divergent mechanism for regulation. Finally, SNF1 is a sensor required for high-affinity glucose transport into the cell for S. cerevisiae (Bisson, 1988). A BLAST search for SNF1 homologs in Y. lipolytica revealed the three above-mentioned genes being the top candidates. This further supports the theory that the mechanism for regulation is more divergent from those seen in S. cerevisiae and it strengthens the case for the three aforementioned genes potentially being implicated in high-affinity glucose uptake in Y. lipolytica.

\section{Outlook}

While sugar assimilation has been well-studied in the conventional S. cerevisiae, the uptake mechanisms, metabolic pathways, and regulatory mechanisms remain poorly understood in Y. lipolytica. To date, much of the work in Y. lipolytica has focused on identifying a few key players involved in hexose assimilation, while engineering toward improved uptake and metabolism of hexose sugars have not been explored as thoroughly. Additionally, efforts have been made to enable the consumption of polysaccharides such as starch (Ledesma-Amaro et al., 2015), cellulose (Wei et al., 2014), cellobiose (Guo et al., 2015), and hemicellulose (Yang et al., 2009). This current review attempts to draw parallels to S. cerevisiae, when possible, with the intention of elucidating potential pathways that could be explored moving forward. Understanding more about the regulatory pathways for hexose metabolism could enable engineering strains capable of improved hexose utilization.

\section{PENTOSE SUBSTRATES}

\section{D-Xylose}

As the most prevalent pentose sugar in hemicellulose, D-xylose is of great interest to the future of biofuels and a biomass economy. Many biotechnologically relevant microbes that can utilize glucose for growth and synthesis of value-added products cannot inherently metabolize D-xylose. With D-xylose making up a large portion of the sugars present in lignocellulosic biomass, enabling its metabolism in model microbial systems could significantly increase the economics of biomass utilization. D-Xylose is poorly metabolized by S. cerevisiae, but is efficiently utilized by Scheffersomyces stipitis, which serves as a model for xylose metabolism. Its metabolism in yeast commonly proceeds through the so-called oxidoreductase pathway; however, some anaerobic fungi have acquired the isomerase pathway through horizontal gene transfer from bacteria (Kuyper et al., 2003). These pathways are shown in Figure 2.

Significant effort has been spent to engineer xylose metabolism in S. cerevisiae. Heterologous expression of S. stipitis genes for xylose reductase $(s s X Y R)$ and a xylitol dehydrogenase (ssXDH) (Kotter et al., 1990) led to improved xylose metabolism. Further analysis of this engineered strain suggested that a third enzyme, a xylulokinase (XKS), is needed to improve xylose utilization and ethanol production (Toivari et al., 2001). Nevertheless, xylose metabolism through the oxidoreductase pathway remains challenging due to redox imbalance (Jin et al., 2004). A comprehensive review of engineered xylose metabolism in S. cerevisiae is available (Kim et al., 2013).

Recently, natural and engineered xylose metabolism has been studied in Y. lipolytica, with the help of genetic engineering and bioinformatics approaches. There have been inconsistent reports describing whether or not xylose could naturally be metabolized by $Y$. lipolytica. While some studies have described native xylose metabolism by $Y$. lipolytica, a majority of the accounts suggest that $Y$. lipolytica cannot utilize xylose without subjecting it to adaptation or starvation periods (Ruiz-Herrera and Sentandreu, 2002; Tsigie et al., 2011; Tai, 2012; Blazeck et al., 2014). 


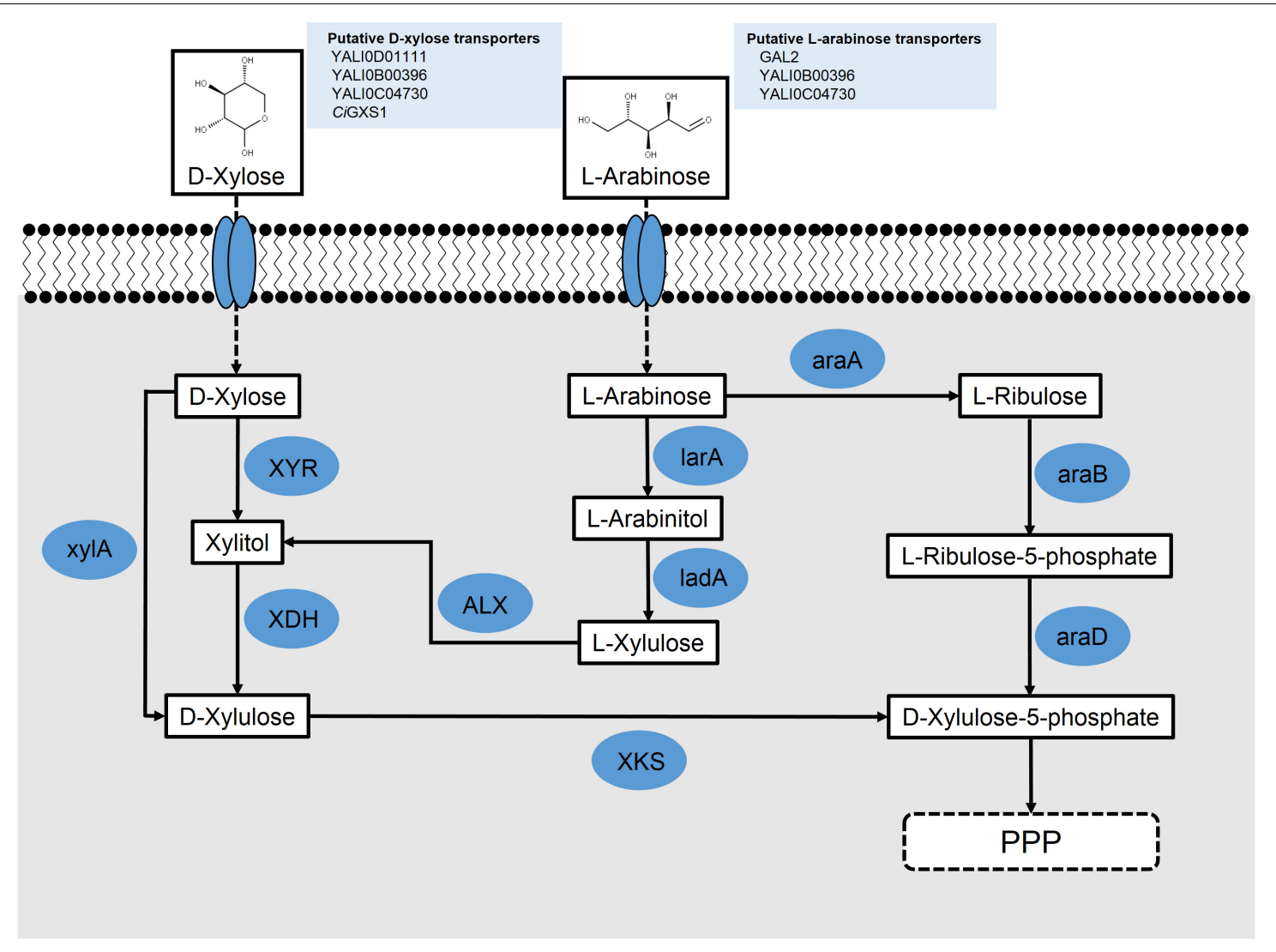

FIGURE 2 | Schematic for the putative metabolism of pentose sugars L-arabinose and D-xylose in engineered Y. lipolytica; L-arabinose reductase (larA) (Aspergillus niger); L-arabinose 4-dehydrogenase (ladA) (A. niger); L-arabinose isomerase (araA) (Bacillus subtilis); L-ribulokinase (araB) (Escherichia coli); L-ribulose-5-phosphate 4-epimerase (araD) (E. coli); L-xylulose reductase (ALX) (Ambrosiozyma monospora); xylose reductase (XYR); xylose dehydrogenase (XDH); xylulokinase (XKS); and xylose isomerase $(x y \mid A)$.

Interestingly, these reports conflicted even among identical strains. In an effort to elucidate and induce xylose metabolism in $Y$. lipolytica, several genetic engineering approaches have been explored. The following four reports were published at approximately the same time. Results from these and other related studies are shown in Table $\mathbf{1}$.

Genome mining suggested that a complete xylose pathway was present in $Y$. lipolytica; however, growth on xylose was not observed in three studies (Ledesma-Amaro and Nicaud, 2016b; Rodriguez et al., 2016), and extremely weak growth was observed in a fourth study after a long period of adaptation (Ryu et al., 2016b). In these weakly growing strains, mRNA expression levels measured with quantitative polymerase chain reaction (qPCR) indicated inducibility of $y l X D H$ gene (YALIOE12463), but overall weak expression (Ryu et al., 2016b). This observation led to their hypothesis that the $y l X D H$ expression was limiting. Overexpression of $y l X D H$ resulted in a significant improvement in growth on xylose after adaptation (Ryu et al., 2016b).

To better understand the intrinsic capability of Y. lipolytica for xylose metabolism, endogenous ylXDH (YALIOE12463) and $y l X K S$ (YALIOF10923) were overexpressed in the PO1f strain under the control of a UAS1B8-TEFmin promoter and a $S$. cerevisiae CYC1 terminator, leading to growth on xylose up to approximately $3 \mathrm{~g} / \mathrm{L}$ DCW, without the need for any adaptation (Rodriguez et al., 2016). This study went further to identify 14 homologs of the $s s X Y R$, of which one enzyme, $y l X Y R 2$ (YALIOF18590), had functional xylose reductase in an Escherichia coli complementation assay; however, its overexpression along with $y l X D H$ and $y l X K S$ did not result in any improvement in growth rate. Overexpression of the native $y l X D H, y l X K S$, and $y l X Y R 1$ (YALIOD07634) under the strong constitutive TEF promoter resulted in very fast growth rates (Niehus et al., 2018). Combined, these results strongly suggest that $Y$. lipolytica has a cryptic metabolism of xylose that is difficult to activate unless under stressed conditions. These data also suggest that $Y$. lipolytica's enzymes have high-specific activity and that its metabolism is already well primed for xylose utilization, unlike S. cerevisiae.

Two groups used heterologous genes to engineer xylose metabolism in Y. lipolytica. Li and Alper (2016) overexpressed ssXYR and ssXDH under a strong hybrid TEF promoter in both PO1f and an evolved lipid-producing strain, requiring a 14-day adaptation to find clones that grew well on xylose. Interestingly, they noted their adaptation resulted from genome duplication events during carbon starvation. Ledesma-Amaro 
TABLE 1 | Summary of recent studies on native and engineered xylose metabolism in Yarrowia lipolytica.

\begin{tabular}{|c|c|c|c|c|c|c|c|c|}
\hline & ssXYR & ssXDH & ssXKS & XYLA & $\frac{\text { XYR }}{\text { YALIOD07634 }}$ & $\frac{\text { XDH }}{\text { YALIOE12463 }}$ & $\frac{\text { XKS }}{\text { YALIOF10923 }}$ & $\begin{array}{l}\text { Growth on xylose } \\
\text { without adaptation? }\end{array}$ \\
\hline \multirow[t]{7}{*}{ Ledesma-Amaro et al., 2016b } & $\checkmark$ & - & - & - & - & - & - & No \\
\hline & - & $\checkmark$ & - & - & - & - & - & No \\
\hline & $\checkmark$ & $\checkmark$ & - & - & - & - & - & No \\
\hline & - & - & - & - & - & - & $\checkmark$ & No \\
\hline & $\checkmark$ & - & - & - & - & - & $\checkmark$ & No \\
\hline & - & $\checkmark$ & - & - & - & - & $\checkmark$ & No \\
\hline & $\checkmark$ & $\checkmark$ & - & - & - & - & $\checkmark$ & Yes \\
\hline Li and Alper, 2016 & $\checkmark$ & $\checkmark$ & - & - & - & - & - & No \\
\hline Li and Alper, 2016 & - & - & - & $\checkmark$ & - & - & - & No \\
\hline Rodriguez et al., 2016 & - & - & - & - & - & $\checkmark$ & $\checkmark$ & Yes \\
\hline Ryu et al., 2016b & - & - & - & - & - & $\checkmark$ & - & No \\
\hline Tai, 2012; Stephanopoulos and Tai, 2015 & $\checkmark$ & $\checkmark$ & - & - & - & - & - & No \\
\hline Niehus et al., 2018 & - & - & - & - & $\checkmark$ & $\checkmark$ & $\checkmark$ & Yes \\
\hline
\end{tabular}

et al. approached engineering xylose metabolism by recognizing that heterologous expression of $s S X Y R$ and $s s X D H$ genes may be insufficient for growth of $Y$. lipolytica as they noted that xylose pathway engineering in $S$. cerevisiae required overexpression of an XKS to convert xylulose into xylulose-5-phosphate and for growth on xylose (Kotter et al., 1990). Using a BLAST search, a putative endogenous $y l X K S$ (YALIOF10923) was found in Y. lipolytica (Ledesma-Amaro and Nicaud, 2016b; Rodriguez et al., 2016). Overexpression of the ssXYR, ssXDK, and $y$ lXKS under the TEF promoter in the PO1d strain of $Y$. lipolytica resulted in growth on xylose of approximately $13 \mathrm{~g} / \mathrm{L}$, similar to wild-type growth on glucose, without the need for adaptation (Ledesma-Amaro et al., 2016b). An alternative approach to enable xylose metabolism in Y. lipolytica involved using a xylose isomerase (xylA) from Piromyces sp., which converts D-xylose into D-xylulose (Figure 2). By this process, the xylA effectively replaces the function of two enzymes, $\mathrm{XYR}$ and $\mathrm{XDH}$, in the xylose pathway. Studies using strains overexpressing $x y l A$ instead of $X Y R$ and $X D H$ together have resulted in strains unable to metabolize xylose, even with adaptive evolution (Li and Alper, 2016). Additionally, BLAST analysis of the xylA protein against $Y$. lipolytica revealed no homologs. Nonetheless, a pathway using xylA and XKS is possible and may be feasible with organism-specific codonoptimization, confirmation that the mRNA expression is optimal, and verification that the protein is being functionally expressed.

\section{L-Arabinose}

Another pentose which is present in hemicellulose and could serve as an alternative carbon source is arabinose. Arabinose catabolism has not been well-characterized in Y. lipolytica; however, limited work has been done to elucidate this pathway (Ryu and Trinh, 2017). L-Arabinose metabolism has been engineered in the conventional yeast, $S$. cerevisiae, by pairing its endogenous galactose permease (GAL2) with bacterial arabinose metabolizing genes: L-Arabinose isomerase (araA) from Bacillus subtilis, L-ribulokinase (araB) from E. coli, and L-ribulose-5phosphate 4-epimerase ( $a r a D)$ also from E. coli (Becker and Boles, 2003).

Protein BLAST using the $S$. cerevisiae GAL2 sequence as a query returned $47 \%$ identity with the endogenous $Y$. lipolytica protein, YALIOF19184p (Figure 2). Neither the B. subtilis araA nor the E. coli araD sequences returned any homologs in Y. lipolytica. One potential araB homolog, YALI0C07722p, was found to share $24 \%$ identity. This suggests that while genetic engineering may be necessary to completely enable L-arabinose metabolism in $Y$. lipolytica, the pathway for L-arabinose metabolism is possibly cryptic like the xylose pathway.

A second route for L-arabinose metabolism has been described for fungi (Chiang and Knight, 1960; Witteveen et al., 1989; Richard et al., 2003; Fonseca et al., 2007). In this pathway, $\mathrm{L}$-arabinose is transported across the cell membrane with the same galactose permease, GAL2, described in the first pathway. It is then converted into L-arabinitol by an L-arabinose reductase. L-Arabinitol is subsequently turned into L-xylulose by an L-arabinitol 4-dehydrogenase. Finally, L-xylulose is converted into xylitol by an L-xylulose reductase, where it can be shuttled through the xylose interconversion pathway and eventually through the pentose phosphate pathway (Figure 2).

A fungal L-arabinose reductase (larA) from Aspergillus niger has been used to convert L-arabinose into L-arabinitol (Mojzita et al., 2010). To determine whether Y. lipolytica might contain a potential larA homolog for the first step in the breakdown of L-arabinose, BLASTp was used with larA as the query. Thirteen hits were found in this search, with the top hit, YALI0F18590p, sharing 93\% coverage and 48\% identity with the reference protein. Interestingly, the next five best hits all shared $90 \%$ coverage and $44 \%$ identity with larA. These results suggest that an L-arabinose metabolizing pathway is very likely to be present in Y. lipolytica either in whole or in part. The fungal L-arabinose 4-dehydrogenase (ladA), also from A. niger, was subjected to BLASTp to find Y. lipolytica homologs. In this case, nine hits resulted, with the top two hits, 
YALI0E12463p and YALI0F09603p, both sharing 86\% coverage and 40 and $24 \%$ identity, respectively, with the ladA protein sequence. YALI0E12463p has been described in work with D-xylose utilization as a xylitol dehydrogenase (Ledesma-Amaro and Nicaud, 2016b; Li and Alper, 2016; Rodriguez et al., 2016). It is possible that overexpression of this protein in Y. lipolytica could enable both the conversion of L-arabinitol to L-xylulose and xylitol to D-xylulose. Because there were substantially more potential homologs found in $Y$. lipolytica using the fungal L-arabinose metabolizing pathway as a reference as opposed to the bacterial pathway, future studies into L-arabinose metabolism will likely focus on this fungal pathway.

The ALX1 protein from the L-arabinose metabolizing yeast, Ambrosiozyma monospora, was first identified as an L-xylulose reductase, which converts L-xylulose into xylitol (Verho et al., 2004). ALX1 has been successfully expressed in S. cerevisiae and, with the expression of an L-arabitol 4-dehydrogenase, growth was observed on media containing L-arabinose as the sole carbon source (Bera et al., 2010). Additionally, a protein BLAST was performed using the ALX1 protein to identify $Y$. lipolytica homologs. The top two hits from this search were YALI0F02211p, with 74\% query coverage and 50\% identity, and YALIOE05643p, with 98\% query coverage and 38\% identity (Figure 2). This suggests that ALX1 can be used as a pathway component to enable L-arabinose metabolism in yeast that do not metabolize L-arabinose naturally and that homologs of ALX1 may already be present in Y. lipolytica.

\section{Pentose Transporters}

The mode by which pentose sugars are transported into $Y$. lipolytica has been debated. In strains that can metabolize D-xylose, for example, the transport mechanism is unclear. Co-utilization studies with glucose and xylose suggest that glucose transporters may be non-specifically transporting xylose across the yeast cell membrane (Sedlak and Ho, 2004). Using known xylose transporters as queries, 22 endogenous genes have been linked to xylose transport in Y. lipolytica through a BLAST analysis (Ryu et al., 2016b). Analysis of the mRNA expression showed that two of these genes, YALI0D01111 and YALI0C04730, were upregulated nearly 10-fold in xylose media (Ryu et al., 2016a). Thirteen other transporters were observed to be upregulated in xylose, suggesting that there could be multiple transporters which help to transport D-xylose across the cell membrane (Nicaud et al., 2017). More recently, Ryu and Trinh (2017) has reiterated that YALI0C04730 and YALI0B00396 function as pentose-specific transporters in Y. lipolytica. These data, along with the fact that xylose metabolism can be enabled with the overexpression of xylose pathway genes, suggest that xylose transport is not a bottleneck for cells utilizing D-xylose as a sole carbon source.

Alternatively, transporters from other yeasts have been engineered to be specific for sugars like D-xylose. A glucose/xylose transporter from Candida intermedia, for example, has been evolved to be a xylose-specific transporter in S. cerevisiae (Young et al., 2014). The main problem with this transporter is that the presence of glucose inhibits xylose transport in dual-substrate cultures. With the goal of enabling simultaneous glucose and xylose metabolism, the ciGXS1 transporter was engineered by directed evolution, resulting in a transporter capable of co-utilization of glucose and xylose with no inhibition ( $\mathrm{Li}$ et al., 2016). This approach may be useful in situations where transport of xylose across the cell membrane is a limiting factor, such as when higher concentrations of xylose or when multiple substrates are used.

\section{Outlook}

The pentose metabolizing capabilities of $Y$. lipolytica have gained attention due to the abundance of pentose sugars in lignocellulosic biomass. With the ever-improving development of bioinformatics and metabolic engineering tools, endogenous sugar utilization pathways are emerging from the Y. lipolytica genome. Although arabinose metabolism has not been wellcharacterized in $Y$. lipolytica, the pathway for arabinose utilization may very well be present, yet cryptic, like xylose metabolism. There are still many questions to answer regarding xylose metabolism; however, progress has been made toward elucidating this pathway from both heterologous and endogenous overexpression of transporters and xylose metabolism enzymes in Y. lipolytica. Improvements which include co-utilization of more than two sugar substrates, more efficient utilization of sugars through cofactor use, and improving product yield will help to make the use of pentose sugars as a feedstock for Y. lipolytica oleochemical production industrially feasible. Another expected improvement is the use of xylan as a substrate for Y. lipolytica engineered for xylose metabolism.

\section{C2 AND C3 SUBSTRATES}

\section{Glycerol}

Many reports characterize glycerol as the preferred substrate for $Y$. lipolytica based on its rapid growth rate (Workman et al., 2013). Furthermore, the tolerance of Y. lipolytica to inhibitory compounds found in crude glycerol justifies the great interest in engineering $Y$. lipolytica to convert unrefined glycerol byproduct of biodiesel production (Andre et al., 2009; Gao C.J. et al., 2016). As such, there is a large body of literature available, including several excellent reviews to which the reader is referred (Rywińska et al., 2013; Leiva-Candia et al., 2014; Samul et al., 2014; Vivek et al., 2017; Yan et al., 2017). For this reason, we do not consider glycerol or crude glycerol as an alternative substrate for the purposes of this review.

\section{Acetate}

The use of acetate as a substrate for Y. lipolytica is promising due to its naturally high flux capacity for acetyl-CoA that is required for lipid efficient lipid accumulation. As a result, there is increasing interest in utilizing acetate or acetic acid as a substrate for Y. lipolytica. Furthermore, acetate can be produced from several low-cost sources, such as syngas $\left(\mathrm{CO} / \mathrm{H}_{2}\right)$, which is abundantly available from gasification of organic material, industrial off-gases, and anaerobic digestion using acetogens equipped with the Wood-Ljungdahl pathway (Lian et al., 2012; Bengelsdorf et al., 2013; Hu et al., 2013; Jiang et al., 2013). Growth 
on acetate requires its activation to acetyl-CoA in the cytoplasm, which is catalyzed by the acetyl-CoA synthetase (ACS) (Liu et al., 2016). Acetate metabolism was studied using ${ }^{13} \mathrm{C}$ flux analysis, showing lipogenic NADPH is made through gluconeogenesis and the oxidative pentose phosphate pathway (Liu et al., 2015).

Recently, an engineered highly lipogenic strain of $Y$. lipolytica (Qiao et al., 2015) was grown in media with $30 \% \mathrm{v} / \mathrm{v}$ acetic acid to produce lipids with a titer of $51 \mathrm{~g} / \mathrm{L}$, a productivity $0.26 \mathrm{~g} / \mathrm{L}-\mathrm{h}$, and $61 \%$ lipid content (Hu et al., 2016). In the same study, similar results ( $46 \mathrm{~g} / \mathrm{L}, 0.27 \mathrm{~g} / \mathrm{L}-\mathrm{h}, 59 \%$ lipids) were achieved using a more dilute acetic acid solution ( $3 \% \mathrm{v} / \mathrm{v})$ using a cell recycling strategy. This process was further optimized and converted to a semicontinuous process leading to $115 \mathrm{~g} / \mathrm{L}, 0.16 \mathrm{~g} / \mathrm{g}$, and $0.8 \mathrm{~g} / \mathrm{L}-\mathrm{h}$ from a $3 \%$ dilute acetic acid media (Xu et al., 2017). Another strain of $Y$. lipolytica was engineered to produce $7.35 \mathrm{~g} / \mathrm{L}$ polyhydroxybutyrate (PHB) (10.2\% of cell dry weight) from a complex media with an acetate carbon source (Li et al., 2017).

\section{Outlook}

Acetate is a promising low-cost substrate for growth and product formation in engineered $Y$. lipolytica strains. Its production from a variety of agroindustrial wastes make it attractive from a sustainability, and potentially economic, perspective. Furthermore, the abundance of acetate produced in biomass pretreatment could provide a significant low-cost source of acetate to use in bioprocesses (Yan et al., 2017). There has been significant progress in using acetate as an alternative substrate through bioprocess control strategies ( $\mathrm{Xu}$ et al., 2017); however, metabolic engineering strategies have not been applied to improving the utilization of acetate. Such strategies include increased acetate tolerance, increased uptake, and improved co-utilization. It is also possible that combining acetate and sugars as a feedstock would provide an energetic advantage for certain bioprocesses.

\section{LIPIDS}

\section{Triacylglycerides}

Triacylglycerides are chemical species composed of three fatty acid chains attached to a glycerol backbone via ester bonds. TAGs serve as the primary form of excess carbon storage in oleaginous yeast, such as Y. lipolytica, and tend to form intracellular lipid bodies (LB) (Athenstaedt et al., 2006). In the presence of sufficient nitrogen and phosphorous, but upon carbon starvation, TAGs can be systematically catabolized to satisfy the carbon requirement. The initial degradation step is carried out by intracellular lipases.

Yarrowia lipolytica possesses 16 genes encoding for lipases and one study suggests that 15 of the 16 lipases are capable of acting intracellularly (Syal and Gupta, 2017). Regardless of location, the first step involves the cleavage of an ester bond to form a free fatty acid and a diacylglycerol (DAG). Figure 3 provides a general schematic of the degradation process. The same lipase can further hydrolyze DAG to produce a second free fatty acid and a monoacylglycerol (MAG). The final step to release a third fatty acid and glycerol is catalyzed by acylglycerol lipase (YALI0C14520p) (Zhao et al., 2011).

In order to metabolize extracellular TAGs as a carbon substrate, Y. lipolytica likely must first degrade TAG to free fatty acids in the extracellular environment as no known TAG transporters have been identified (Beopoulos et al., 2009). Three extracellular lipases have been characterized in the Y. lipolytica literature: LIP2 (YALI0A20350p), LIP7 (YALI0D19184p), and LIP8 (YALI0B09361p) (Fickers et al., 2005). In strains with all three of these lipase genes knocked out, cells were unable to grow on lipid substrates as the sole carbon source. Fickers et al. (2005) suggest that this is strong evidence supporting the claim that no other extracellular lipases exist in Y. lipolytica.

LIP2 makes up the majority of the expressed extracellular lipases and has been extensively studied (Pignede et al., 2000). Due to its high expression and secretion, LIP2 was used as one of the model systems for excretory enzymes in this yeast (Nicaud et al., 2002). Extracellular lipases LIP7 and LIP8, as characterized by Fickers et al. (2005), have amino acid sequence similarities to LIP2 of 33.9 and $35.2 \%$, respectively. Compared to one another, LIP7 and LIP8 share 76\% homology. The three extracellular lipases also possess differing substrate specificities. While all of these enzymes show a broad, normally distributed range of action, LIP2 tends to act on longer-chain lipids ( $Y u$ et al., 2007) and LIP7/LIP8 prefer shorter species, with the highest activity on 6-carbon/10-carbon compounds, respectively (Fickers et al., 2005).

The locations of these extracellular-acting lipases also differ. LIP2 is most commonly found in the bulk media during stationary phase; however, it is believed to be closely associated to the cell membrane during log phase growth. On the other hand, LIP7 and LIP8 appear to remain bound to cell membrane during the entire growth cycle; however, they may be released from the membrane under conditions of stationary phase carbon starvation (Fickers et al., 2005). Once the extracellular lipases have hydrolyzed TAGs, the free fatty acids and glycerol must be transported into the cell to be metabolized.

\section{Free Fatty Acids}

Uptake of free fatty acids from the bulk phase is believed to occur by either transporter or diffusion at concentrations above $10 \mu \mathrm{M}$ (Kohlwein and Paltauf, 1984). Once in the cytoplasm, free fatty acids may be bound by a fatty acid-binding protein (FABP, YALIOE01298), activated by conversion into a fatty acyl-CoA by cytoplasmic fatty acyl-CoA synthase (FAA1, YALIOD17864p), or directly transported into the peroxisome (Dulermo et al., 2015; Ledesma-Amaro et al., 2016a). The fatty acyl-CoA enters the peroxisome via the membranebound transport protein pair PXA1 (YALI0A06655p) and PXA2 (YALI0D04246p) (Dulermo et al., 2015). The fatty acids/acylCoAs that enter the peroxisome can then be degraded by the well-studied $\beta$-oxidation cycle. Recent work from our group reveals synergistic effects of glycerol and fatty acid mixtures on the expression of $\beta$-oxidation gene, POX2 (Shabbir Hussain et al., 2017). Alternatively, the fatty acyl-CoA can enter the endoplasmic reticulum for incorporation into cellular lipids or TAGs (Figure 4). 


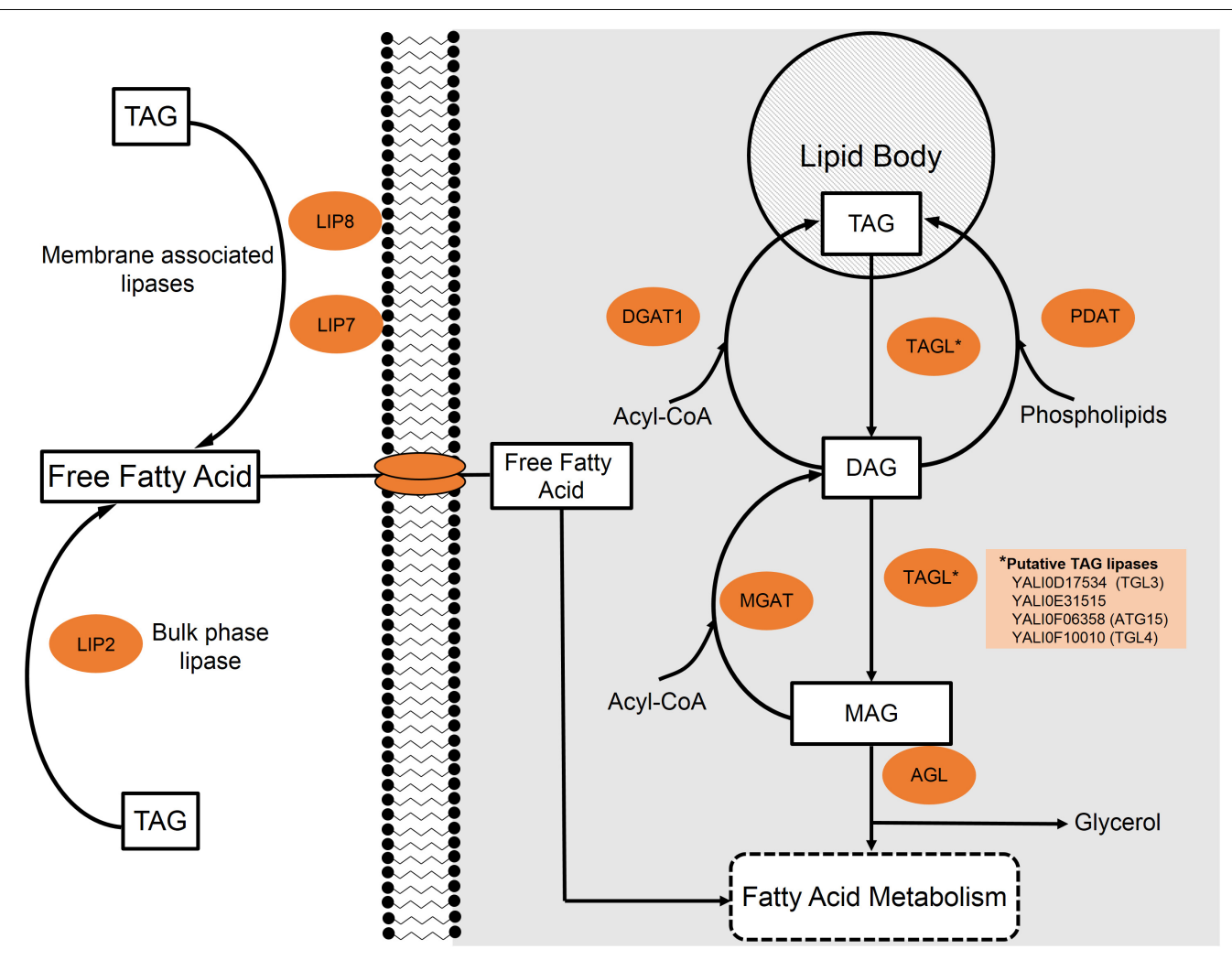

FIGURE 3 | Lipid metabolism of triacylglycerides (TAGs) in Y. lipolytica. Extracellular and intracellular TAGs are processed through a stepwise degradation pathway focusing around either extracellular lipases (Lip2, Lip7, and Lip8) or internal triacylglycerol lipases (TGLs), respectively.

\section{Olive Oil Mill Waste}

Olive mill wastewater (OMW) is a waste stream produced by the processing of raw olives and contains water, olive tissue, sugars, polyphenolics, oils, and high amounts of salts especially $\mathrm{Na}^{+}, \mathrm{K}^{+}$, and ${ }^{-} \mathrm{HCO}_{3}$ species (Aly et al., 2014). One report estimates OMW production from Mediterranean countries alone at 30 million $\mathrm{m}^{3}$ - approximately 7.9 billion gallons (Mekki et al., 2013). OMW contains a substantial amount of phenolics that must be removed prior to further remediation and wastewater treatment (Aggelis et al., 2003).

Yarrowia lipolytica's robust growth on a variety of substrates and tolerance for usually hostile growth media makes it an ideal candidate for remediation and valorization of OMW (Aly et al., 2014). Recent work demonstrated growth on glucosesupplemented OMW. A lipid composition of $48 \%$, as well as $19 \mathrm{~g} / \mathrm{L}$ citric acid production, was achieved on this mixed media (Sarris et al., 2017). Additionally, a post-fermentation assay of OMW phenolic concentration showed a decrease of up to $13.8 \%$, suggesting a potential route for simultaneous remediation and valorization.

\section{Animal Fats}

Much of the literature focuses on the production of lipids in Y. lipolytica; however, as the name suggests, it has a robust capability to break down fats and oils (lipolytic) as a carbon source. Of particular interest is waste animal fats. With relatively low market value, valorization of this waste stream has substantial economic potential. Kamzolova et al. (2005) characterized Y. lipolytica's growth and lipase production on rendered beef fat. The authors demonstrated biomass accumulations of between 2.5 and $5.3 \mathrm{~g} / \mathrm{L}$ DCW from media containing $10 \mathrm{~g} / \mathrm{L}$ animal fat and $10 \mathrm{~g} / \mathrm{L}$ peptone. Citric acid and isocitric acid yields of up to 18 and $5.2 \mathrm{~g} / \mathrm{L}$, respectively, were achieved on the animal fat containing media. Growth has also been demonstrated on derivatives of animal waste fat. Stearin (fat derivative), glucose, and waste glycerol were used to produce $3.4 \mathrm{~g} / \mathrm{L}$ of a cocoa-butter-like lipid mixture high in stearic acid (Papanikolaou et al., 2003). In order to reach this yield, a high carbon-to-nitrogen ratio of 175:1 and the emulsifying agents Tween 80 and PEG 20,000 were required.

\section{Agro-Industrial Waste}

Waste cooking oil (WCO) has already received substantial attention for its role as a synthetic biodiesel feedstock; however, it may also have potential as a substrate for Y. lipolytica. Demonstrating the flexibility of $Y$. lipolytica to convert a dissimilar feed to a new product, Xiaoyan et al. (2017) used WCO to produce the sugar alcohol erythritol. Currently, commercial erythritol is biologically produced from higher-cost glucose that has often been obtained via enzymatic hydrolysis of starch 


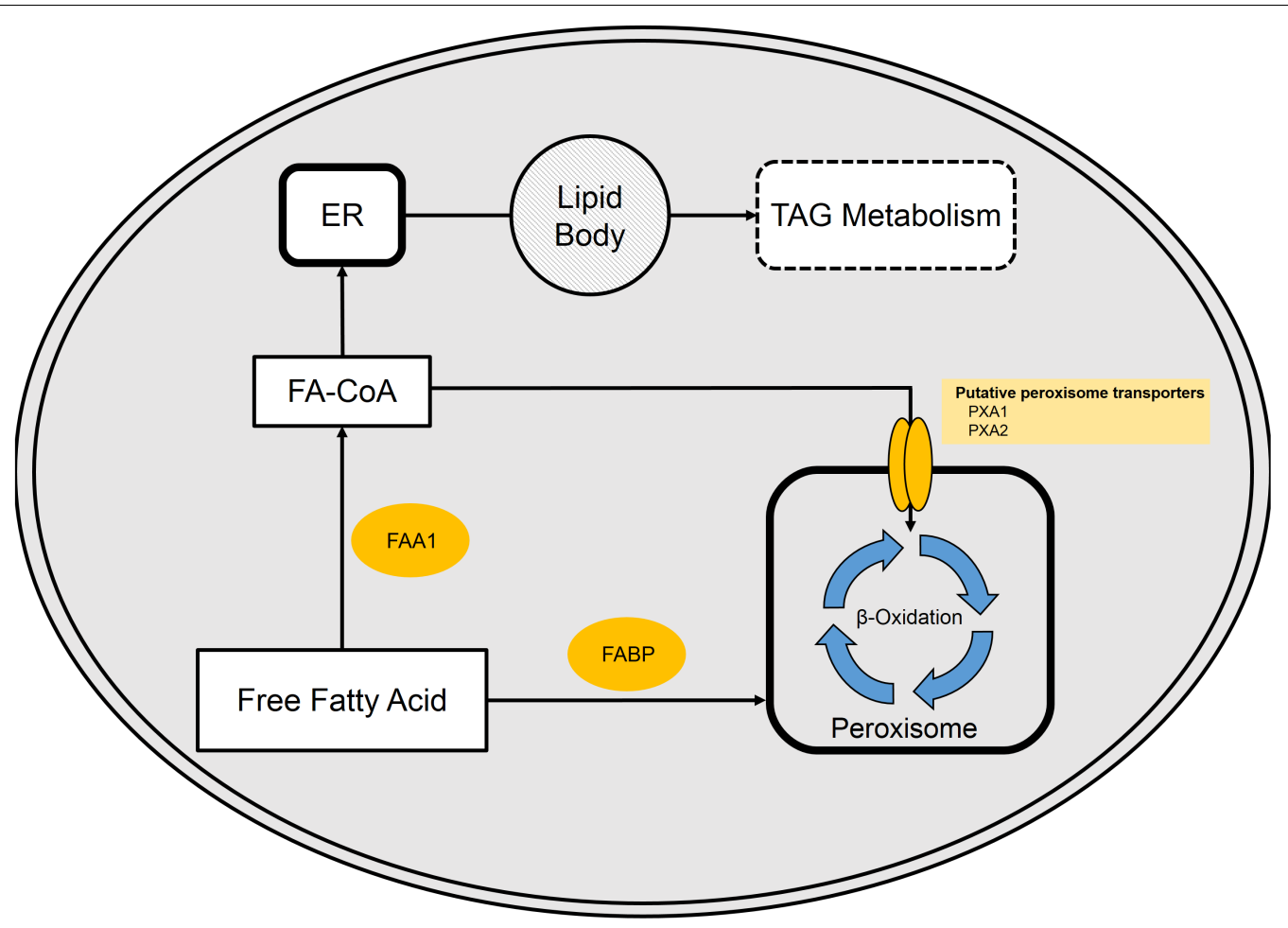

FIGURE 4 | Free fatty acid (FFA) metabolism in Y. lipolytica. FFA present in the cytosol are bound by fatty acid-binding protein (FABP). Once bound, FAs either enter the peroxisome or are activated via fatty acyl-CoA synthase (FAA1). Activated FA (fatty acyl-CoAs) is either funneled into the peroxisome or enter the TAG synthesis pathway.

or other polysaccharides (Aoki et al., 1993). The cost of this multi-step, expensive procedure could potentially be greatly reduced by making use of non-sugar waste streams, such as WCO.

Unlike most of the aforementioned feedstocks, which serve primarily as sources of carbon, crustacean waste has been investigated as a potential nitrogen source to support the growth of Y. lipolytica (Magdouli et al., 2017). In their work, Magdouli et al. (2017) made use of crude glycerol and crustacean waste to produce $38 \mathrm{U} / \mathrm{mL}$ of lipase in $Y$. lipolytica. They also demonstrated similar levels of lipase production on other carbon waste sources such as used vegetable, olive oil, and motor oil.

The growing demand for palm oil has resulted in an increased supply of the waste product palm kernel cake (PKC). Of particular interest, this solid material contains $16.1 \%$ (w/w) protein and, when supplemented with glucose, was able to support the growth of Y. lipolytica (Imandi et al., 2010). Under these conditions, lipase yields of $18.58 \mathrm{U} / \mathrm{g}$ of PKC were possible.

\section{Outlook}

The turn toward waste streams as potential feedstocks has opened up many potential routes for the symbiosis of biotechnology and sustainable manufacturing practices. Bioremediation, waste valorization, and in situ processing of byproducts present possible large-scale applications of appropriately engineered microorganisms. The myriad alternative carbon and nitrogen sources on which $Y$. lipolytica can grow suggests that it has the necessary properties to fill such a role. The advancement of bioinformatics tools allows for increasingly complex and accurate modeling of species fluxes within the organism. As the available genetic toolbox grows, important questions must be answered for further advances. Specifically, much is still unknown regarding the interaction between pathways, their activation, and their inhibition. This is of particular interest when considering growth on complex, undefined, and often inhospitable feeds. Metabolic engineering efforts to utilize waste substrates are likely to focus on relieving inhibitory effects of substrate contaminants and relieving cross-pathway regulatory effects.

\section{CONCLUSION}

There is considerable interest in the use of alternative substrates due to bioprocess economics and sustainability. This interest is justified only if microbial systems can be engineered to efficiently use these substrates and tolerate contaminants and the regulatory effects of multiple species that can be metabolized. Y. lipolytica is well poised to enable the use of alternative feedstocks at large scale due to its natural tolerance to many chemical conditions and the wide array of products it can easily be engineered to produce. We expect future work in the field to begin applying metabolic engineering strategies to better utilize diverse and often unrefined substrates. 


\section{AUTHOR CONTRIBUTIONS}

MSH, LG, MS, and MB participated in writing, editing, and approving the final manuscript.

\section{FUNDING}

This work was supported by NSF CBET-1403099 (MB), CBET-1706134 (MB), as well as Creative Inquiry funds from Clemson University. This work was also supported

\section{REFERENCES}

Adrio, J. L. (2017). Oleaginous yeasts: promising platforms for the production of oleochemicals and biofuels. Biotechnol. Bioeng. 114, 1915-1920. doi: 10.1002/ bit. 26337

Aggelis, G., Iconomou, D., Christou, M., Bokas, D., Kotzailias, S., Christou, G., et al. (2003). Phenolic removal in a model olive oil mill wastewater using Pleurotus ostreatus in bioreactor cultures and biological evaluation of the process. Water Res. 37, 3897-3904.

Aly, A. A., Hasan, Y. N., and Al-Farraj, A. S. (2014). Olive mill wastewater treatment using a simple zeolite-based low-cost method. J. Environ. Manage. 145, 341-348. doi: 10.1016/j.jenvman.2014.07.012

Andre, A., Chatzifragkou, A., Diamantopoulou, P., Sarris, D., Philippoussis, A., Galiotou-Panayotou, M., et al. (2009). Biotechnological conversions of biodiesel-derived crude glycerol by Yarrowia lipolytica strains. Eng. Life Sci. 9, 468-478.

Aoki, M. A. Y., Pastore, G. M., and Park, Y. K. (1993). Microbial transformation of sucrose and glucose to erythritol. Biotechnol. Lett. 15, 383-388.

Athenstaedt, K., Jolivet, P., Boulard, C., Zivy, M., Negroni, L., Nicaud, J. M., et al. (2006). Lipid particle composition of the yeast Yarrowia lipolytica depends on the carbon source. Proteomics 6, 1450-1459.

Bajwa, W., Torchia, T. E., and Hopper, J. E. (1988). Yeast regulatory gene GAL3: carbon regulation; UASGal elements in common with GAL1, GAL2, GAL7, GAL10, GAL80, and MEL1; encoded protein strikingly similar to yeast and Escherichia coli galactokinases. Mol. Cell. Biol. 8, 3439-3447.

Batista, A. S., Miletti, L. C., and Stambuk, B. U. (2004). Sucrose fermentation by Saccharomyces cerevisiae lacking hexose transport. J. Mol. Microbiol. Biotechnol. $8,26-33$.

Becker, J., and Boles, E. (2003). A modified Saccharomyces cerevisiae strain that consumes L-arabinose and produces ethanol. Appl. Environ. Microbiol. 69, 4144-4150.

Bengelsdorf, F. R., Straub, M., and Durre, P. (2013). Bacterial synthesis gas (syngas) fermentation. Environ. Technol. 34, 1639-1651.

Beopoulos, A., Chardot, T., and Nicaud, J. M. (2009). Yarrowia lipolytica: a model and a tool to understand the mechanisms implicated in lipid accumulation. Biochimie 91, 692-696. doi: 10.1016/j.biochi.2009. 02.004

Bera, A. K., Sedlak, M., Khan, A., and Ho, N. W. (2010). Establishment of L-arabinose fermentation in glucose/xylose co-fermenting recombinant Saccharomyces cerevisiae $424 \mathrm{~A}(\mathrm{LNH}-\mathrm{ST})$ by genetic engineering. Appl. Microbiol. Biotechnol. 87, 1803-1811. doi: 10.1007/s00253-0102609-0

Bisson, L. F. (1988). High-affinity glucose transport in Saccharomyces cerevisiae is under general glucose repression control. J. Bacteriol. 170, 4838-4845.

Blazeck, J., and Alper, H. S. (2013). Promoter engineering: recent advances in controlling transcription at the most fundamental level. Biotechnol. J. 8, 46-58. doi: 10.1002/biot.201200120

Blazeck, J., Hill, A., Liu, L., Knight, R., Miller, J., Pan, A., et al. (2014). Harnessing Yarrowia lipolytica lipogenesis to create a platform for lipid and biofuel production. Nat. Commun. 5:3131. doi: 10.1038/ncomms4131

Blazeck, J., Liu, L., Redden, H., and Alper, H. (2011). Tuning gene expression in Yarrowia lipolytica by a hybrid promoter approach. Appl. Environ. Microbiol. 77, 7905-7914. doi: 10.1128/AEM.05763-11 by an Early Career Faculty grant from NASA's Space Technology Research Grants Program (MB), and funding from the Animal Co-Products Research and Education Center, with funding from the Fats and Protein Research Foundation (MB).

\section{ACKNOWLEDGMENTS}

The authors would like to acknowledge Allison Yaguchi and Dyllan Rives for their helpful comments.

Blazeck, J., Reed, B., Garg, R., Gerstner, R., Pan, A., Agarwala, V., et al. (2013). Generalizing a hybrid synthetic promoter approach in Yarrowia lipolytica. Appl. Microbiol. Biotechnol. 97, 3037-3052. doi: 10.1007/s00253-012-4421-5

Celińska, E., Ledesma-Amaro, R., Larroude, M., Rossignol, T., Pauthenier, C., and Nicaud, J. M. (2017). Golden gate assembly system dedicated to complex pathway manipulation in Yarrowia lipolytica. Microb. Biotechnol. 10, 450-455. doi: 10.1111/1751-7915.12605

Chiang, C., and Knight, S. G. (1960). Metabolism of d-xylose by moulds. Nature 188, 79-81.

Chiba, Y., Suzuki, M., Yoshida, S., Yoshida, A., Ikenaga, H., Takeuchi, M., et al. (1998). Production of human compatible high mannose-type (Man5GlcNAc2) sugar chains in Saccharomyces cerevisiae. J. Biol. Chem. 273, 26298-26304.

Coelho, M., Amaral, P., and Belo, I. (2010). "Yarrowia lipolytica: an industrial workhorse," in Current Research, Technology and Education Topics in Applied Microbiology and Microbial Biotechnology, Vol. 2, 2nd Edn, ed. A. MendezVillas (Badajoz: Formatex), 930-940.

Colabardini, A. C., Ries, L. N., Brown, N. A., Dos Reis, T. F., Savoldi, M., Goldman, M. H., et al. (2014). Functional characterization of a xylose transporter in Aspergillus nidulans. Biotechnol. Biofuels 7:46. doi: 10.1186/1754-6834-7-46

Curran, K. A., Morse, N. J., Markham, K. A., Wagman, A. M., Gupta, A., and Alper, H. S. (2015). Short synthetic terminators for improved heterologous gene expression in yeast. ACS Synth. Biol. 4, 824-832. doi: 10.1021/sb5003357

Douglas, H. C., and Hawthorne, D. C. (1964). Enzymatic expression and genetic linkage of genes controlling galactose utilization in Saccharomyces. Genetics 49, 837-844.

Drysdale, M. R., Kolze, S. E., and Kelly, J. M. (1993). The Aspergillus niger carbon catabolite repressor encoding gene, creA. Gene 130, 241-245. doi: 10.1016/ 0378-1119(93)90425-3

Du Preez, J., Bosch, M., and Prior, B. (1986). The fermentation of hexose and pentose sugars by Candida shehatae and Pichia stipitis. Appl. Microbiol. Biotechnol. 23, 228-233. doi: 10.1007/BF00261920

Dulermo, R., Brunel, F., Dulermo, T., Ledesma-Amaro, R., Vion, J., Trassaert, M., et al. (2017). Using a vector pool containing variable-strength promoters to optimize protein production in Yarrowia lipolytica. Microb. Cell Fact. 16:31. doi: 10.1186/s12934-017-0647-3

Dulermo, R., Gamboa-Melendez, H., Ledesma-Amaro, R., Thevenieau, F., and Nicaud, J. M. (2015). Unraveling fatty acid transport and activation mechanisms in Yarrowia lipolytica. Biochim. Biophys. Acta 1851, 1202-1217. doi: 10.1016/j. bbalip.2015.04.004

Escalante-Chong, R., Savir, Y., Carroll, S. M., Ingraham, J. B., Wang, J., Marx, C. J., et al. (2015). Galactose metabolic genes in yeast respond to a ratio of galactose and glucose. Proc. Natl. Acad. Sci. U.S.A. 112, 1636-1641. doi: 10.1073/pnas. 1418058112

Ezekowitz, R. A., Sastry, K., Bailly, P., and Warner, A. (1990). Molecular characterization of the human macrophage mannose receptor: demonstration of multiple carbohydrate recognition-like domains and phagocytosis of yeasts in Cos-1 cells. J. Exp. Med. 172, 1785-1794. doi: 10.1084/jem.172.6.1785

Fickers, P., Fudalej, F., Le Dall, M. T., Casaregola, S., Gaillardin, C., Thonart, P., et al. (2005). Identification and characterisation of LIP7 and LIP8 genes encoding two extracellular triacylglycerol lipases in the yeast Yarrowia lipolytica. Fungal Genet. Biol. 42, 264-274. doi: 10.1016/j.fgb.2004.12.003

Fonseca, C., Spencer-Martins, I., and Hahn-Hagerdal, B. (2007). L-Arabinose metabolism in Candida arabinofermentans PYCC 5603T and Pichia 
guilliermondii PYCC 3012: influence of sugar and oxygen on product formation. Appl. Microbiol. Biotechnol. 75, 303-310. doi: 10.1007/s00253-006-0830-7

Fukuda, Y., Yamaguchi, S., Shimosaka, M., Murata, K., and Kimura, A. (1984). Purification and characterization of glucokinase in Escherichia coli B. Agric. Biol. Chem. 48, 2541-2548. doi: 10.1271/bbb1961.48.2541

Gancedo, J. M., Clifton, D., and Fraenkel, D. G. (1977). Yeast hexokinase mutants. J. Biol. Chem. 252, 4443-4444.

Gao, C. J., Yang, X. F., Wang, H. M., Rivero, C. P., Li, C., Cui, Z. Y., et al. (2016). Robust succinic acid production from crude glycerol using engineered Yarrowia lipolytica. Biotechnol. Biofuels 9:179. doi: 10.1186/s13068-016-0597-8

Gao, S., Tong, Y., Wen, Z., Zhu, L., Ge, M., Chen, D., et al. (2016). Multiplex gene editing of the Yarrowia lipolytica. J. Ind. Microbiol. Biotechnol. 43, 1085-1093. doi: 10.1007/s10295-016-1789-8

Gao, S., Tong, Y., Zhu, L., Ge, M., Jiang, Y., Chen, D., et al. (2017). Production of $\beta$-carotene by expressing a heterologous multifunctional carotene synthase in Yarrowia lipolytica. Biotechnol. Lett. 39, 921-927. doi: 10.1007/s10529-0172318-1

Gil, F. N., Moreira-Santos, M., Chelinho, S., Pereira, C., Feliciano, J. R., Leitao, J. H., et al. (2015). Suitability of a Saccharomyces cerevisiae-based assay to assess the toxicity of pyrimethanil sprayed soils via surface runoff: comparison with standard aquatic and soil toxicity assays. Sci. Total Environ. 505, 161-171. doi: 10.1016/j.scitotenv.2014.09.094

Gottschalk, A. (1946). The mechanism of selective fermentation of D-fructose from invert sugar by sauternes yeast. Biochem. J. 40, 621-626. doi: 10.1042/bj0400621

Guo, Z., Duquesne, S., Bozonnet, S., Cioci, G., Nicaud, J.-M., Marty, A., et al. (2015). Development of cellobiose-degrading ability in Yarrowia lipolytica strain by overexpression of endogenous genes. Biotechnol. Biofuels 8:109. doi: 10.1186/s13068-015-0289-9

Hamilton, S. R., Bobrowicz, P., Bobrowicz, B., Davidson, R. C., Li, H., Mitchell, T., et al. (2003). Production of complex human glycoproteins in yeast. Science 301, 1244-1246. doi: 10.1126/science. 1088166

Hong, S. P., Seip, J., Walters-Pollak, D., Rupert, R., Jackson, R., Xue, Z., et al. (2012). Engineering Yarrowia lipolytica to express secretory invertase with strong FBA1IN promoter. Yeast 29, 59-72. doi: 10.1002/yea.1917

Hu, P., Chakraborty, S., Kumar, A., Woolston, B., Liu, H. J., Emerson, D., et al. (2016). Integrated bioprocess for conversion of gaseous substrates to liquids. Proc. Natl. Acad. Sci. U.S.A. 113, 3773-3778. doi: 10.1073/pnas.1516867113

Hu, P., Rismani-Yazdi, H., and Stephanopoulos, G. (2013). Anaerobic CO2 fixation by the acetogenic bacterium Moorella thermoacetica. AIChE J. 59, 3176-3183. doi: 10.1002/aic.14127

Hussain, M. S., Rodriguez, G. M., Gao, D. F., Spagnuolo, M., Gambill, L., and Blenner, M. (2016). Recent advances in bioengineering of the oleaginous yeast Yarrowia lipolytica. AIMS Bioeng. 3, 493-514. doi: 10.3934/bioeng.2016.4.493

Imandi, S. B., Karanam, S. K., and Garapati, H. R. (2010). Optimization of media constituents for the production of lipase in solid state fermentation by Yarrowia lipolytica from palm Kernal cake (Elaeis guineensis). Adv. Biosci. Biotechnol. 1:115. doi: 10.4236/abb.2010.12016

Jiang, J. G., Zhang, Y. J., Li, K. M., Wang, Q., Gong, C. X., and Li, M. L. (2013). Volatile fatty acids production from food waste: effects of $\mathrm{pH}$, temperature, and organic loading rate. Bioresour. Technol. 143, 525-530. doi: 10.1016/j.biortech. 2013.06.025

Jin, Y. S., Laplaza, J. M., and Jeffries, T. W. (2004). Saccharomyces cerevisiae engineered for xylose metabolism exhibits a respiratory response. Appl. Environ. Microbiol. 70, 6816-6825. doi: 10.1128/AEM.70.11.6816-6825.2004

John, T. P. S., and Davis, R. W. (1979). Isolation of galactose-inducible DNA sequences from Saccharomyces cerevisiae by differential plaque filter hybridization. Cell 16, 443-452. doi: 10.1016/0092-8674(79)90020-5

Jordan, P., Choe, J. Y., Boles, E., and Oreb, M. (2016). Hxt13, Hxt15, Hxt16 and Hxt17 from Saccharomyces cerevisiae represent a novel type of polyol transporters. Sci. Rep. 6:23502. doi: 10.1038/srep23502

Kamzolova, S. V., Morgunov, I. G., Aurich, A., Perevoznikova, O. A., Shishkanova, N. V., Stottmeister, U., et al. (2005). Lipase secretion and citric acid production in Yarrowia lipolytica yeast grown on animal and vegetable fat. Food Technol. Biotechnol. 43, 113-122.

Kildegaard, K. R., Adiego-Pérez, B., Belda, D. D., Khangura, J. K., Holkenbrink, C., and Borodina, I. (2017). Engineering of Yarrowia lipolytica for production of astaxanthin. Synth. Syst. Biotechnol. 2, 287-294. doi: 10.1016/j.synbio.2017. 10.002
Kim, D., Song, J. Y., and Hahn, J. S. (2015). Improvement of glucose uptake rate and production of target chemicals by overexpressing hexose transporters and transcriptional activator Gcrl in Saccharomyces cerevisiae. Appl. Environ. Microbiol. 81, 8392-8401. doi: 10.1128/AEM.02056-15

Kim, S. R., Park, Y. C., Jin, Y. S., and Seo, J. H. (2013). Strain engineering of Saccharomyces cerevisiae for enhanced xylose metabolism. Biotechnol. Adv. 31, 851-861. doi: 10.1016/j.biotechadv.2013.03.004

Kohlwein, S. D., and Paltauf, F. (1984). Uptake of fatty acids by the yeasts, Saccharomyces uvarum and Saccharomycopsis lipolytica. Biochim. Biophys. Acta 792, 310-317. doi: 10.1016/0005-2760(84)90198-X

Kotter, P., Amore, R., Hollenberg, C. P., and Ciriacy, M. (1990). Isolation and characterization of the Pichia stipitis xylitol dehydrogenase gene, XYL2, and construction of a xylose-utilizing Saccharomyces cerevisiae transformant. Curr. Genet. 18, 493-500. doi: 10.1007/BF00327019

Kuyper, M., Harhangi, H. R., Stave, A. K., Winkler, A. A., Jetten, M. S., De Laat, W. T., et al. (2003). High-level functional expression of a fungal xylose isomerase: the key to efficient ethanolic fermentation of xylose by Saccharomyces cerevisiae? FEMS Yeast Res. 4, 69-78.

Lazar, Z., Dulermo, T., Neuveglise, C., Crutz-Le Coq, A. M., and Nicaud, J. M. (2014). Hexokinase-A limiting factor in lipid production from fructose in Yarrowia lipolytica. Metab. Eng. 26, 89-99. doi: 10.1016/j.ymben.2014.09.008

Lazar, Z., Gamboa-Melendez, H., Le Coq, A. M., Neuveglise, C., and Nicaud, J. M. (2015). Awakening the endogenous Leloir pathway for efficient galactose utilization by Yarrowia lipolytica. Biotechnol. Biofuels 8:185. doi: 10.1186/ s13068-015-0370-4

Lazar, Z., Neuveglise, C., Rossignol, T., Devillers, H., Morin, N., Robak, M., et al. (2017). Characterization of hexose transporters in Yarrowia lipolytica reveals new groups of sugar porters involved in yeast growth. Fungal Genet. Biol. 100, 1-12. doi: 10.1016/j.fgb.2017.01.001

Lazar, Z., Rossignol, T., Verbeke, J., Crutz-Le Coq, A. M., Nicaud, J. M., and Robak, M. (2013). Optimized invertase expression and secretion cassette for improving Yarrowia lipolytica growth on sucrose for industrial applications. J. Ind. Microbiol. Biotechnol. 40, 1273-1283. doi: 10.1007/s10295-013$1323-1$

Ledesma-Amaro, R., Dulermo, R., Niehus, X., and Nicaud, J.-M. (2016a). Combining metabolic engineering and process optimization to improve production and secretion of fatty acids. Metab. Eng. 38, 38-46. doi: 10.1016/j. ymben.2016.06.004

Ledesma-Amaro, R., Dulermo, T., and Nicaud, J. M. (2015). Engineering Yarrowia lipolytica to produce biodiesel from raw starch. Biotechnol. Biofuels 8:148. doi: 10.1186/s13068-015-0335-7

Ledesma-Amaro, R., Lazar, Z., Rakicka, M., Guo, Z., Fouchard, F., Crutz-Le Coq, A.-M., et al. (2016b). Metabolic engineering of Yarrowia lipolytica to produce chemicals and fuels from xylose. Metab. Eng. 38, 115-124. doi: 10.1016/j.ymben. 2016.07.001

Ledesma-Amaro, R., and Nicaud, J. M. (2016a). Metabolic engineering for expanding the substrate range of Yarrowia lipolytica. Trends Biotechnol. 34, 798-809. doi: 10.1016/j.tibtech.2016.04.010

Ledesma-Amaro, R., and Nicaud, J. M. (2016b). Yarrowia lipolytica as a biotechnological chassis to produce usual and unusual fatty acids. Prog. Lipid Res. 61, 40-50. doi: 10.1016/j.plipres.2015.12.001

Leiva-Candia, D. E., Pinzi, S., Redel-Macias, M. D., Koutinas, A., Webb, C., and Dorado, M. P. (2014). The potential for agro-industrial waste utilization using oleaginous yeast for the production of biodiesel. Fuel 123, 33-42. doi: 10.1016/ j.fuel.2014.01.054

Li, H., and Alper, H. S. (2016). Enabling xylose utilization in Yarrowia lipolytica for lipid production. Biotechnol. J. 11, 1230-1240. doi: 10.1002/biot.20160 0210

Li, H. B., Schmitz, O., and Alper, H. S. (2016). Enabling glucose/xylose co-transport in yeast through the directed evolution of a sugar transporter. Appl. Microbiol. Biotechnol. 100, 10215-10223. doi: 10.1007/s00253-016-7879-8

Li, Z. J., Qiao, K. J., Liu, N., and Stephanopoulos, G. (2017). Engineering Yarrowia lipolytica for poly-3-hydroxybutyrate production. J. Ind. Microbiol. Biotechnol. 44, 605-612. doi: 10.1007/s10295-016-1864-1

Lian, J. N., Garcia-Perez, M., Coates, R., Wu, H. W., and Chen, S. L. (2012). Yeast fermentation of carboxylic acids obtained from pyrolytic aqueous phases for lipid production. Bioresour. Technol. 118, 177-186. doi: 10.1016/j.biortech. 2012.05.010 
Liu, L., Pan, A., Spofford, C., Zhou, N., and Alper, H. S. (2015). An evolutionary metabolic engineering approach for enhancing lipogenesis in Yarrowia lipolytica. Metab. Eng. 29, 36-45. doi: 10.1016/j.ymben.2015.02.003

Liu, N., Qiao, K. J., and Stephanopoulos, G. (2016). C-13 Metabolic Flux Analysis of acetate conversion to lipids by Yarrowia lipolytica. Metab. Eng. 38, 86-97. doi: 10.1016/j.ymben.2016.06.006

Luyten, K., Riou, C., and Blondin, B. (2002). The hexose transporters of Saccharomyces cerevisiae play different roles during enological fermentation. Yeast 19, 713-726. doi: 10.1002/yea.869

Ma, H., and Botstein, D. (1986). Effects of null mutations in the hexokinase genes of Saccharomyces cerevisiae on catabolite repression. Mol. Cell. Biol. 6, 4046-4052. doi: 10.1128/MCB.6.11.4046

Madzak, C., Gaillardin, C., and Beckerich, J.-M. (2004). Heterologous protein expression and secretion in the non-conventional yeast Yarrowia lipolytica: a review. J. Biotechnol. 109, 63-81. doi: 10.1016/j.jbiotec.2003.10.027

Magdouli, S., Guedri, T., Tarek, R., Brar, S. K., and Blais, J. F. (2017). Valorization of raw glycerol and crustacean waste into value added products by Yarrowia lipolytica. Bioresour. Technol. 243, 57-68. doi: 10.1016/j.biortech.2017.06.074

Maitra, P. K. (1970). A glucokinase from Saccharomyces cerevisiae. J. Biol. Chem. 245, 2423-2431.

Mekki, A., Dhouib, A., and Sayadi, S. (2013). Effects of olive mill wastewater application on soil properties and plants growth. Int. J. Recycl. Org. Waste Agric. 2, 1-7. doi: 10.1186/2251-7715-2-15

Moeller, L., Zehnsdorf, A., Aurich, A., Bley, T., and Strehlitz, B. (2012). Substrate utilization by recombinant Yarrowia lipolytica growing on sucrose. Appl. Microbiol. Biotechnol. 93, 1695-1702. doi: 10.1007/s00253-011-3681-9

Mojzita, D., Herold, S., Metz, B., Seiboth, B., and Richard, P. (2012). L-xylo3-hexulose reductase is the missing link in the oxidoreductive pathway for D-galactose catabolism in filamentous fungi. J. Biol. Chem. 287, 26010-26018. doi: 10.1074/jbc.M112.372755

Mojzita, D., Penttilä, M., and Richard, P. (2010). Identification of an L-arabinose reductase gene in Aspergillus niger and its role in L-arabinose catabolism. J. Biol. Chem. 285, 23622-23628. doi: 10.1074/jbc.M110.113399

Nicaud, J. M., Fabre, E., Beckerich, J. M., Fournier, P., and Gaillardin, C. (1989a). Cloning, sequencing and amplification of the alkaline extracellular protease (Xpr2) gene of the yeast Yarrowia-Lipolytica. J. Biotechnol. 12, 285-298. doi: 10.1016/0168-1656(89)90048-5

Nicaud, J.-M., Fabre, E., and Gaillardin, C. (1989b). Expression of invertase activity in Yarrowia lipolytica and its use as a selective marker. Curr. Genet. 16, 253-260.

Nicaud, J.-M., Lazar, Z., Dulermo, T., and Crutz-Le Coq, A.-M. (2017). Improved Lipid Accumulation in Yarrowia lipolytica Strains by Overexpression of Hexokinase and New Strains Thereof. U.S. Patent No 6,090,051. Washington, DC: U.S. Patent and Trademark Office.

Nicaud, J. M., Madzak, C., Van Den Broek, P., Gysler, C., Duboc, P., Niederberger, P., et al. (2002). Protein expression and secretion in the yeast Yarrowia lipolytica. FEMS Yeast Res. 2, 371-379.

Niehus, X., Crutz-Le Coq, A.-M., Sandoval, G., Nicaud, J.-M., and LedesmaAmaro, R. (2018). Engineering Yarrowia lipolytica to enhance lipid production from lignocellulosic materials. Biotechnol. Biofuels 11:11. doi: 10.1186/s13068018-1010-6

Ostergaard, S., Olsson, L., Johnston, M., and Nielsen, J. (2000). Increasing galactose consumption by Saccharomyces cerevisiae through metabolic engineering of the GAL gene regulatory network. Nat. Biotechnol. 18, 1283-1286. doi: 10.1038/ 82400

Papanikolaou, S., Muniglia, L., Chevalot, I., Aggelis, G., and Marc, I. (2003). Accumulation of a cocoa-butter-like lipid by Yarrowia lipolytica cultivated on agro-industrial residues. Curr. Microbiol. 46, 124-130. doi: 10.1007/s00284002-3833-3

Park, J. N., Song, Y., Cheon, S. A., Kwon, O., Oh, D. B., Jigami, Y., et al. (2011). Essential role of YlMPO1, a novel Yarrowia lipolytica homologue of Saccharomyces cerevisiae MNN4, in mannosylphosphorylation of N- and O-linked glycans. Appl. Environ. Microbiol. 77, 1187-1195. doi: 10.1128/AEM. 02323-10

Pignede, G., Wang, H., Fudalej, F., Gaillardin, C., Seman, M., and Nicaud, J. M. (2000). Characterization of an extracellular lipase encoded by LIP2 in Yarrowia lipolytica. J. Bacteriol. 182, 2802-2810. doi: 10.1128/JB.182.10.2802-2810.2000

Platt, A., Ross, H. C., Hankin, S., and Reece, R. J. (2000). The insertion of two amino acids into a transcriptional inducer converts it into a galactokinase.
Proc. Natl. Acad. Sci. U.S.A. 97, 3154-3159. doi: 10.1073/pnas.97.7. 3154

Qiao, K., Imam Abidi, S. H., Liu, H., Zhang, H., Chakraborty, S., Watson, N., et al. (2015). Engineering lipid overproduction in the oleaginous yeast Yarrowia lipolytica. Metab. Eng. 29, 56-65. doi: 10.1016/j.ymben.2015.02.005

Rajesh, T., Song, E., Kim, J. N., Lee, B. R., Kim, E. J., Park, S. H., et al. (2012). Inactivation of phosphomannose isomerase gene abolishes sporulation and antibiotic production in Streptomyces coelicolor. Appl. Microbiol. Biotechnol. 93, 1685-1693. doi: 10.1007/s00253-011-3581-z

Richard, P., Verho, R., Putkonen, M., Londesborough, J., and Penttila, M. (2003). Production of ethanol from L-arabinose by Saccharomyces cerevisiae containing a fungal L-arabinose pathway. FEMS Yeast Res. 3, 185-189. doi: 10.1016/S15671356(02)00184-8

Rintala, E., Wiebe, M. G., Tamminen, A., Ruohonen, L., and Penttila, M. (2008). Transcription of hexose transporters of Saccharomyces cerevisiae is affected by change in oxygen provision. BMC Microbiol. 8:53. doi: 10.1186/1471-2180-8-53

Rodriguez, A., De La Cera, T., Herrero, P., and Moreno, F. (2001). The hexokinase 2 protein regulates the expression of the GLK1, HXK1 and HXK2 genes of Saccharomyces cerevisiae. Biochem. J. 355, 625-631. doi: 10.1042/bj3550625

Rodriguez, G. M., Hussain, M. S., Gambill, L., Gao, D., Yaguchi, A., and Blenner, M. (2016). Engineering xylose utilization in Yarrowia lipolytica by understanding its cryptic xylose pathway. Biotechnol. Biofuels 9:149. doi: 10.1186/s13068-0160562-6

Ruiz-Herrera, J., and Sentandreu, R. (2002). Different effectors of dimorphism in Yarrowia lipolytica. Arch. Microbiol. 178, 477-483. doi: 10.1007/s00203-0020478-3

Ryu, S., Hipp, J., and Trinh, C. T. (2016a). Activating and elucidating metabolism of complex sugars in Yarrowia lipolytica. Appl. Environ. Microbiol. 82, 1334-1345. doi: 10.1128/AEM.03582-15

Ryu, S., Hipp, J., and Trinh, C. T. (2016b). Erratum for Ryu et al., activating and elucidating metabolism of complex sugars in Yarrowia lipolytica. Appl. Environ. Microbiol. 82:2572. doi: 10.1128/AEM.00457-16

Ryu, S., Labbe, N., and Trinh, C. T. (2015). Simultaneous saccharification and fermentation of cellulose in ionic liquid for efficient production of alpha-ketoglutaric acid by Yarrowia lipolytica. Appl. Microbiol. Biotechnol. 99, 4237-4244. doi: 10.1007/s00253-015-6521-5

Ryu, S., and Trinh, C. T. (2017). Understanding functional roles of native pentosespecific transporters for activating dormant pentose metabolism in Yarrowia lipolytica. Appl. Environ. Microbiol. 84:e02146-17. doi: 10.1128/AEM.02146-17

Rywińska, A., Juszczyk, P., Wojtatowicz, M., Robak, M., Lazar, Z., Tomaszewska, L., et al. (2013). Glycerol as a promising substrate for Yarrowia lipolytica biotechnological applications. Biomass Bioenergy 48, 148-166. doi: 10.1016/j. biombioe.2012.11.021

Sabra, W., Bommareddy, R. R., Maheshwari, G., Papanikolaou, S., and Zeng, A. P. (2017). Substrates and oxygen dependent citric acid production by Yarrowia lipolytica: insights through transcriptome and fluxome analyses. Microb. Cell Fact. 16:78. doi: 10.1186/s12934-017-0690-0

Sagnak, R., Cochot, S., Molina-Jouve, C., Nicaud, J.-M., and Guillouet, S. E. (2018). Modulation of the glycerol phosphate availability led to concomitant reduction in the citric acid excretion and increase in lipid content and yield in Yarrowia lipolytica. J. Biotechnol. 265, 40-45. doi: 10.1016/j.jbiotec.2017.11.001

Samul, D., Leja, K., and Grajek, W. (2014). Impurities of crude glycerol and their effect on metabolite production. Ann. Microbiol. 64, 891-898. doi: 10.1007/ s13213-013-0767-x

Sarris, D., Stoforos, N. G., Mallouchos, A., Kookos, I. K., Koutinas, A. A., Aggelis, G., et al. (2017). Production of added-value metabolites by Yarrowia lipolytica growing in olive mill wastewater-based media under aseptic and non-aseptic conditions. Eng. Life Sci. 17, 695-709. doi: 10.1002/elsc.201600225

Schultz, L. D., Hofmann, K. J., Mylin, L. M., Montgomery, D. L., Ellis, R. W., and Hopper, J. E. (1987). Regulated overproduction of the GAL4 gene product greatly increases expression from galactose-inducible promoters on multi-copy expression vectors in yeast. Gene 61, 123-133. doi: 10.1016/0378-1119(87) 90107-7

Schwartz, C., Frogue, K., Misa, J., and Wheeldon, I. (2017a). Host and pathway engineering for enhanced lycopene biosynthesis in Yarrowia lipolytica. Front. Microbiol. 8:2233. doi: 10.3389/fmicb.2017.02233

Schwartz, C. M., Hussain, M. S., Blenner, M., and Wheeldon, I. (2016). Synthetic RNA polymerase III promoters facilitate 
high-efficiency CRISPR-Cas9-mediated genome editing in Yarrowia lipolytica. ACS Synth. Biol. 5, 356-359. doi: 10.1021/acssynbio.5b0 0162

Schwartz, C., Shabbir-Hussain, M., Frogue, K., Blenner, M., and Wheeldon, I. (2017b). Standardized markerless gene integration for pathway engineering in Yarrowia lipolytica. ACS Synth. Biol. 6, 402-409. doi: 10.1021/acssynbio. $6 \mathrm{~b} 00285$

Sedlak, M., and Ho, N. W. (2004). Characterization of the effectiveness of hexose transporters for transporting xylose during glucose and xylose co-fermentation by a recombinant Saccharomyces yeast. Yeast 21, 671-684. doi: 10.1002/yea. 1060

Shabbir Hussain, M., Gambill, L., Smith, S., and Blenner, M. A. (2016). Engineering promoter architecture in oleaginous yeast Yarrowia lipolytica. ACS Synth. Biol. 5, 213-223. doi: 10.1021/acssynbio.5b00100

Shabbir Hussain, M., Wheeldon, I., and Blenner, M. A. (2017). A strong hybrid fatty acid inducible transcriptional sensor built from Yarrowia lipolytica upstream activating and regulatory sequences. Biotechnol. J. 12:1700248. doi: 10.1002/ biot.201700248

Sharifpoor, S., Ba, A. N. N., Young, J.-Y., Van Dyk, D., Friesen, H., Douglas, A. C., et al. (2011). A quantitative literature-curated gold standard for kinase-substrate pairs. Genome Biol. 12:R39. doi: 10.1186/gb-2011-12-4-r39

Sigdel, S., Singh, R., Kim, T. S., Li, J., Kim, S. Y., Kim, I. W., et al. (2015). Characterization of a mannose-6-phosphate isomerase from Bacillus amyloliquefaciens and its application in Fructose-6-phosphate production. PLoS One 10:e131585. doi: 10.1371/journal.pone.0131585

Stephanopoulos, G., and Tai, M. (2015). Engineered Microbes and Methods for Microbial Oil Overproduction from Cellulosic Materials. U.S. Patent No 6,090,051. Washington, DC: U.S. Patent and Trademark Office.

Subtil, T., and Boles, E. (2012). Competition between pentoses and glucose during uptake and catabolism in recombinant Saccharomyces cerevisiae. Biotechnol. Biofuels 5:14. doi: 10.1186/1754-6834-5-14

Suzuki, Y., Nogi, Y., Abe, A., and Fukasawa, T. (1988). GAL11 protein, an auxiliary transcription activator for genes encoding galactose-metabolizing enzymes in Saccharomyces cerevisiae. Mol. Cell. Biol. 8, 4991-4999. doi: 10.1128/MCB.8.11. 4991

Syal, P., and Gupta, R. (2017). Heterologous expression of lipases YLIP4, YLIP5, YLIP7, YLIP13, and YLIP15 from Yarrowia lipolytica MSR80 in Escherichia coli: substrate specificity, kinetic comparison, and enantioselectivity. Biotechnol. Appl. Biochem. 64, 851-861. doi: 10.1002/bab.1542

Tai, M. (2012). Metabolic Engineering of Oleaginous Yeast for the Production of Biofuels. Cambridge, MA: Massachusetts Institute of Technology.

Thevenieau, F., Nicaud, J.-M., and Gaillardin, C. (2009). "Applications of the non-conventional yeast Yarrowia lipolytica," in Yeast Biotechnology: Diversity and Applications, eds T. Satyanarayana and G. Kunze (Dordrecht: Springer), 589-613.

Tiels, P., Baranova, E., Piens, K., De Visscher, C., Pynaert, G., Nerinckx, W., et al. (2012). A bacterial glycosidase enables mannose-6-phosphate modification and improved cellular uptake of yeast-produced recombinant human lysosomal enzymes. Nat. Biotechnol. 30, 1225-1231. doi: 10.1038/nbt.2427

Timson, D. J. (2007). Galactose metabolism in Saccharomyces cerevisiae. Dyn. Biochem. Process Biotechnol. Mol. Biol. 1, 63-73.

Toivari, M. H., Aristidou, A., Ruohonen, L., and Penttila, M. (2001). Conversion of xylose to ethanol by recombinant Saccharomyces cerevisiae: importance of xylulokinase (XKS1) and oxygen availability. Metab. Eng. 3, 236-249. doi: 10.1006/mben.2000.0191

Tsigie, Y. A., Wang, C. Y., Truong, C. T., and Ju, Y. H. (2011). Lipid production from Yarrowia lipolytica Polg grown in sugarcane bagasse hydrolysate. Bioresour. Technol. 102, 9216-9222. doi: 10.1016/j.biortech.2011.06.047

Verho, R., Putkonen, M., Londesborough, J., Penttila, M., and Richard, P. (2004). A novel NADH-linked l-xylulose reductase in the l-arabinose catabolic pathway of yeast. J. Biol. Chem. 279, 14746-14751. doi: 10.1074/jbc.M312533200

Vivek, N., Sindhu, R., Madhavan, A., Anju, A. J., Castro, E., Faraco, V., et al. (2017). Recent advances in the production of value added chemicals and lipids utilizing biodiesel industry generated crude glycerol as a substrate - Metabolic aspects, challenges and possibilities: an overview. Bioresour. Technol. 239, 507-517. doi: 10.1016/j.biortech.2017.05.056

Wang, G. K., Xiong, X. C., Ghogare, R., Wang, P. D., Meng, Y. H., and Chen, S. L. (2016). Exploring fatty alcohol-producing capability of Yarrowia lipolytica. Biotechnol. Biofuels 9:107. doi: 10.1186/s13068-016-0512-3
Wei, H., Wang, W., Alahuhta, M., Vander Wall, T., Baker, J. O., Taylor, L. E., et al. (2014). Engineering towards a complete heterologous cellulase secretome in Yarrowia lipolytica reveals its potential for consolidated bioprocessing. Biotechnol. Biofuels 7:148. doi: 10.1186/s13068-014-0148-0

Witteveen, C. F. B., Busink, R., Vandevondervoort, P., Dijkema, C., Swart, K., and Visser, J. (1989). L-Arabinose and D-Xylose catabolism in Aspergillus niger. J. Gen. Microbiol. 135, 2163-2171. doi: 10.1099/00221287-135-8-2163

Workman, M., Holt, P., and Thykaer, J. (2013). Comparing cellular performance of Yarrowia lipolytica during growth on glucose and glycerol in submerged cultivations. AMB Express 3:58. doi: 10.1186/2191-0855-3-58

Xiaoyan, L., Yu, X., Lv, J., Xu, J., Xia, J., Wu, Z., et al. (2017). A costeffective process for the coproduction of erythritol and lipase with Yarrowia lipolytica M53 from waste cooking oil. Food Bioprod. Process. 103, 86-94. doi: 10.1016/j.fbp.2017.03.002

Xie, D., Miller, E., Sharpe, P., Jackson, E., and Zhu, Q. (2017). Omega-3 production by fermentation of Yarrowia lipolytica: from fed-batch to continuous. Biotechnol. Bioeng. 114, 798-812. doi: 10.1002/bit.26216

Xu, J. Y., Liu, N., Qiao, K. J., Vogg, S., and Stephanopoulos, G. (2017). Application of metabolic controls for the maximization of lipid production in semicontinuous fermentation. Proc. Natl. Acad. Sci. U.S.A. 114, E5308-E5316. doi: 10.1073/pnas.1703321114

Xu, P., Qiao, K. J., Ahn, W. S., and Stephanopoulos, G. (2016). Engineering Yarrowia lipolytica as a platform for synthesis of drop-in transportation fuels and oleochemicals. Proc. Natl. Acad. Sci. U.S.A. 113, 10848-10853. doi: 10.1073/ pnas. 1607295113

Xue, Z., Sharpe, P. L., Hong, S. P., Yadav, N. S., Xie, D., Short, D. R., et al. (2013). Production of omega-3 eicosapentaenoic acid by metabolic engineering of Yarrowia lipolytica. Nat. Biotechnol. 31, 734-740. doi: 10.1038/nbt.2622

Yan, J. Y., Yan, Y. J., Madzak, C., and Han, B. N. (2017). Harnessing biodiesel-producing microbes: from genetic engineering of lipase to metabolic engineering of fatty acid biosynthetic pathway. Crit. Rev. Biotechnol. 37, 26-36. doi: 10.3109/07388551.2015.1104531

Yang, X. S., Jiang, Z. B., Song, H. T., Jiang, S. J., Madzak, C., and Ma, L. X. (2009). Cell-surface display of the active mannanase in Yarrowia lipolytica with a novel surface-display system. Biotechnol. Appl. Biochem. 54, 171-176. doi: 10.1042/BA20090222

Young, E. M., Tong, A., Bui, H., Spofford, C., and Alper, H. S. (2014). Rewiring yeast sugar transporter preference through modifying a conserved protein motif. Proc. Natl. Acad. Sci. U.S.A. 111, 131-136. doi: 10.1073/pnas.1311970111

Yu, M., Lange, S., Richter, S., Tan, T., and Schmid, R. D. (2007). High-level expression of extracellular lipase Lip2 from Yarrowia lipolytica in Pichia pastoris and its purification and characterization. Protein Expr. Purif. 53, 255-263. doi: $10.1016 /$ j.pep.2006.10.018

Yuzbashev, T. V., Yuzbasheva, E. Y., Sobolevskaya, T. I., Laptev, I. A., Vybornaya, T. V., Larina, A. S., et al. (2010). Production of succinic acid at low pH by a recombinant strain of the aerobic yeast Yarrowia lipolytica. Biotechnol. Bioeng. 107, 673-682. doi: 10.1002/bit.22859

Zhao, H., Zheng, L., Wang, X., Liu, Y., Xu, L., and Yan, Y. (2011). Cloning, expression and characterization of a new lipase from Yarrowia lipolytica. Biotechnol. Lett. 33, 2445-2452. doi: 10.1007/s10529-011-0711-8

Zhu, Y., Jiang, J.-L., Gumlaw, N. K., Zhang, J., Bercury, S. D., Ziegler, R. J., et al. (2009). Glycoengineered acid $\alpha$-glucosidase with improved efficacy at correcting the metabolic aberrations and motor function deficits in a mouse model of Pompe disease. Mol. Ther. 17, 954-963. doi: 10.1038/mt.2009.37

Zimmermann, F. K., and Scheel, I. (1977). Mutants of Saccharomyces cerevisiae resistant to carbon catabolite repression. Mol. Gen. Genet. 154, 75-82. doi: $10.1007 /$ BF00265579

Conflict of Interest Statement: The authors declare that the research was conducted in the absence of any commercial or financial relationships that could be construed as a potential conflict of interest.

Copyright (®) 2018 Spagnuolo, Shabbir Hussain, Gambill and Blenner. This is an open-access article distributed under the terms of the Creative Commons Attribution License (CC BY). The use, distribution or reproduction in other forums is permitted, provided the original author(s) and the copyright owner are credited and that the original publication in this journal is cited, in accordance with accepted academic practice. No use, distribution or reproduction is permitted which does not comply with these terms. 